\title{
Experimental Investigation of the Application of Microramp Flow Control to an Oblique Shock Interaction
}

Stefanie M. Hirt and Bernhard H. Anderson

Glenn Research Center, Cleveland, Ohio 


\section{NASA STI Program . . . in Profile}

Since its founding, NASA has been dedicated to the advancement of aeronautics and space science. The NASA Scientific and Technical Information (STI) program plays a key part in helping NASA maintain this important role.

The NASA STI Program operates under the auspices of the Agency Chief Information Officer. It collects, organizes, provides for archiving, and disseminates NASA's STI. The NASA STI program provides access to the NASA Aeronautics and Space Database and its public interface, the NASA Technical Reports Server, thus providing one of the largest collections of aeronautical and space science STI in the world. Results are published in both non-NASA channels and by NASA in the NASA STI Report Series, which includes the following report types:

- TECHNICAL PUBLICATION. Reports of completed research or a major significant phase of research that present the results of NASA programs and include extensive data or theoretical analysis. Includes compilations of significant scientific and technical data and information deemed to be of continuing reference value. NASA counterpart of peer-reviewed formal professional papers but has less stringent limitations on manuscript length and extent of graphic presentations.

- TECHNICAL MEMORANDUM. Scientific and technical findings that are preliminary or of specialized interest, e.g., quick release reports, working papers, and bibliographies that contain minimal annotation. Does not contain extensive analysis.

- CONTRACTOR REPORT. Scientific and technical findings by NASA-sponsored contractors and grantees.
- CONFERENCE PUBLICATION. Collected papers from scientific and technical conferences, symposia, seminars, or other meetings sponsored or cosponsored by NASA.

- SPECIAL PUBLICATION. Scientific, technical, or historical information from NASA programs, projects, and missions, often concerned with subjects having substantial public interest.

- TECHNICAL TRANSLATION. Englishlanguage translations of foreign scientific and technical material pertinent to NASA's mission.

Specialized services also include creating custom thesauri, building customized databases, organizing and publishing research results.

For more information about the NASA STI program, see the following:

- Access the NASA STI program home page at http://www.sti.nasa.gov

- E-mail your question via the Internet to help@ sti.nasa.gov

- Fax your question to the NASA STI Help Desk at $443-757-5803$

- Telephone the NASA STI Help Desk at 443-757-5802

- Write to: NASA Center for AeroSpace Information (CASI) 7115 Standard Drive Hanover, MD 21076-1320 


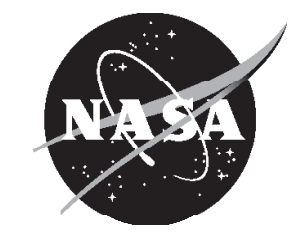

\section{Experimental Investigation of the Application of Microramp Flow Control to an Oblique Shock Interaction}

Stefanie M. Hirt and Bernhard H. Anderson

Glenn Research Center, Cleveland, Ohio

Prepared for the

47th Aerospace Sciences Meeting

sponsored by the American Institute of Aeronautics and Astronautics

Orlando, Florida, January 5-8, 2009

National Aeronautics and

Space Administration

Glenn Research Center

Cleveland, Ohio 44135 
This work was sponsored by the Fundamental Aeronautics Program at the NASA Glenn Research Center.

Level of Review: This material has been technically reviewed by technical management.

Available from

NASA Center for Aerospace Information

7115 Standard Drive

Hanover, MD 21076-1320
National Technical Information Service 5285 Port Royal Road Springfield, VA 22161

Available electronically at http://gltrs.grc.nasa.gov 


\title{
Experimental Investigation of the Application of Microramp Flow Control to an Oblique Shock Interaction
}

\author{
Stefanie M. Hirt and Bernhard H. Anderson \\ National Aeronautics and Space Administration \\ Glenn Research Center \\ Cleveland, Ohio 44135
}

\begin{abstract}
The effectiveness of microramp flow control devices in controlling an oblique shock interaction was tested in the 15- by 15-Centimeter Supersonic Wind Tunnel at NASA Glenn Research Center. Fifteen microramp geometries were tested varying the height, chord length, and spacing between ramps. Measurements of the boundary layer properties downstream of the shock reflection were analyzed using design of experiments methods. Results from main effects, D-optimal, full factorial, and central composite designs were compared. The designs provided consistent results for a single variable optimization.
\end{abstract}

\section{Nomenclature}

$\begin{array}{ll}\mathrm{A}_{\mathrm{p}} & \begin{array}{l}\text { microramp half angle } \\ \mathrm{a}\end{array} \\ c & \begin{array}{l}\text { response equation coefficient } \\ \text { microramp chord length }\end{array} \\ H & \text { incompressible shape factor } \\ h & \text { microramp height } \\ \mathrm{M} & \text { Mach number } \\ \mathrm{M}_{\mathrm{b}} & \text { Mach number for the shock only baseline case } \\ S & \text { microramp spacing } \\ U & \text { streamwise velocity } \\ U_{\infty} & \text { freestream streamwise velocity } \\ \mathrm{X}_{\mathrm{p}} & \text { microramp centerline position } \\ \delta & \text { boundary layer thickness } \\ \delta^{*} & \text { boundary layer displacement thickness } \\ \theta & \text { boundary layer momentum thickness }\end{array}$

\section{Introduction}

A supersonic inlet is used to decelerate and compress the flow before it enters the engine. In mixed compression inlets, a series of reflected oblique shocks decelerate the flow to around Mach 1.3 before a normal shock brings the flow to subsonic conditions. Where these shocks impact the wall shock boundary layer interactions (SBLIs) thicken and possibly separate the boundary layer.

Bleed has become the standard means of reducing the effects of the boundary layer. Part of the low velocity flow in the boundary layer is removed, leaving a higher average flow velocity in the inlet. However, since air is being removed from the system, the inlet must be larger to provide the same total mass flow to the engine, and the bleed flow is typically dumped overboard, which adds significant drag. Microramp flow control devices (refs. 1 and 2) are another potential means of controlling boundary layers 
through SBLIs that are of interest as an alternative to bleed due to their low weight and mechanical simplicity.

Microramp flow control devices have the potential to improve the flow downstream of an oblique shock by increasing the velocity near the wall. The counter-rotating vortices generated by the microramp flow control devices mix the higher momentum flow from the outer portion of the boundary layer-and for larger microramps the edge of the core flow-with the flow near the wall. This creates an increase in the near-wall velocity at the cost of creating a deficit farther from the wall.

Vortex generators have been used in subsonic diffusers to avoid separation due to flow turning angles. In this test, the vortex generators were located in the supersonic flow upstream of the shock interaction to condition the flow prior to the interaction. Microramps also differ from traditional vortex generators in their size. While traditional vortex generators typically have heights on the order of the boundary layer thickness, microramp heights are on the order of 20 to 50 percent of the boundary layer thickness.

A test was conducted in the 15- by 15-Centimeter Supersonic Wind Tunnel at NASA Glenn Research Center to test the effectiveness of microramp flow control devices on an oblique shock interaction. Fifteen microramp geometries were tested using design of experiment (DOE) techniques (ref. 3). The variables studied were the height, $h$; chord length, $c$; and spacing between ramps, $s$.

Data was also taken for three baseline cases for comparison to the microramp performance. The baseline cases included the tunnel with no microramps and no shock, the tunnel with microramps and no shock, and the tunnel with a shock and no microramps. For all cases, boundary layer pitot pressure surveys were taken at 10 spanwise positions to examine the three-dimensional influence of the ramps.

This paper discusses the results from the DOE analysis examining how the incompressible shape factor and boundary layer thickness vary throughout the test space and comparing various orders of modeling. The measured flowfields downstream of the oblique shock reflection are also examined to gain insight into the effects revealed by the DOE analysis.

\section{Test Setup}

\section{A. 15- by 15-Centimeter Supersonic Wind Tunnel}

The 15- by 15-Centimeter Supersonic Wind Tunnel, shown in figure 1, is a continuous flow facility in the Engine Research Building at NASA Glenn Research Center. The inflow is connected to the central air supply which provides $40 \mathrm{psig}(280 \mathrm{kPa})$ pressure at ambient temperature. This supply air is regulated by an upstream valve that is controlled to maintain a constant test section total pressure. The exhaust exits to the central altitude exhaust system, which can sustain pressures less than $2.0 \mathrm{psia}(14 \mathrm{kPa})$.

The test section has a constant area of 5.91 by $5.91 \mathrm{in} .(15.0$ by $15.0 \mathrm{~cm})$ and has configurable insert sections on each of the four walls. Downstream of the test section the flow encounters a rearward facing step where the tunnel area expands to a 9.25 by 9.25 in. $(23.5$ by $23.5 \mathrm{~cm})$ section.

The tunnel Mach 2.0 nozzle block was used for this test. The inlet total pressure was set to give a Reynolds number of $4.00 \mathrm{E} 6 / \mathrm{ft}(13.1 \mathrm{E} 6 / \mathrm{m})$. During the test the Reynolds number was monitored so that the measured value was held within $\pm 0.02 \mathrm{E} 6 / \mathrm{ft}(0.07 \mathrm{E} 6 / \mathrm{m})$. A shock generator plate was mounted on the removable sidewalls to provide an oblique shock at a nominal incidence angle of $8.5^{\circ}$. An actuation system in the downstream expanded section allowed the tunnel to be started with the plate at a lower angle. Because of error in the positioning system for the shock generator plate, the angle was measured with an inclinometer after each run. Based on the measurements, the mean shock incidence angle during the testing was $8.46^{\circ}$ with a standard deviation of $0.03^{\circ}$.

The layout of the oblique shock in the tunnel can be seen in figure 2 . The tunnel centerline was defined as $\mathrm{z}=0 \mathrm{~cm}$, and the inviscid shock impingement was selected as $\mathrm{x}=0 \mathrm{~cm}$. The microramps were inserted onto the tunnel wall in the supersonic flow upstream of the shock. The microramp centerline was positioned at $\mathrm{x}=-13 \mathrm{~cm}$. 


\section{B. Microramps}

The microramps were positioned with their centerline at $\mathrm{x}_{\mathrm{p}}=-13 \mathrm{~cm}$. Figure 3 shows the microramps geometry variables. The height, $h$; the spacing, $s$; and the chord length, $c$, were varied. The microramp half-angle, $A_{p}$, was held constant at $24^{\circ}$. The heights studied were 3,4 , and $5 \mathrm{~mm}$. The spacings were 25,30 , and $35 \mathrm{~mm}$, and the chord lengths were 12, 18, and $24 \mathrm{~mm}$. Within these ranges DOE methodology was used to select the specific microramp geometry configurations to test. Fifteen configurations were built and tested as shown in figure 4 . To reduce the effects of corner interactions on the measurements, an array of three microramps was centered in the tunnel with measurements taken from $\mathrm{z}=-\mathrm{s} / 2$ to $\mathrm{s} / 2$ across the center microramp. A picture of three of the microramp inserts that were tested is shown in figure 5.

\section{Instrumentation and Data Systems}

The primary measurement plane was located $\mathrm{x}=4 \mathrm{~cm}$ for all cases tested in which the oblique shock was present. This location was chosen to avoid influence of the expansion fan from the back of the shock generator plate on the measurements. A remotely actuated instrumentation arm capable of translation in the $y$ - and z-directions was used to translate a pitot probe to collect boundary layer profiles over 10 spanwise (z) locations and 30 transverse (y) locations. The pitot probe tip was flattened to allow measurements near the wall. The probing pattern is shown in figure 6 with each intersection representing a measurement point. Since symmetry is expected about $z=0 \mathrm{~cm}$ (in line with the microramp tip), six equally spaced profiles were taken at positive $\mathrm{z}$-values, one at $\mathrm{z}=0 \mathrm{~cm}$, and only three at negative z-values to confirm symmetry. A total of 25 static pressure taps were arrayed on the tunnel wall as shown in figure 7. Steady state pressure values were supplied to ESCORT, the NASA Glenn steady state data acquisition system, as acquired by the pressure measurement system.

\section{Design of Experiments}

The outcome of a DOE analysis is a predicted response surface. For this experiment the response variables chosen were the boundary layer thickness and the incompressible shape factor. The predicted response surface is defined by an equation that describes how the response variable changes as a function of the factor variables (in this case, $s, h$, and $c$ ) within the design space. The response surface equation can be used to estimate the value of the response variable at configurations that were not tested.

The boundary layer thickness, $\delta$, was selected as a response parameter because it provides information on the extent to which the vortex impacts the core flow. The incompressible shape factor, $H$, was chosen primarily because it has been used to quantify improvements in boundary layer health for bleed flows (ref. 4). The incompressible shape factor is typically used instead of the compressible form even in compressible flow because it is independent of Mach number. A flat plate turbulent boundary layer has an incompressible shape factor of approximately 1.3 at all Mach numbers, and a boundary layer near separation has an incompressible shape factor of about 2.7 (ref. 5).

The values of the factor variable that were held constant were determined through a DOE screening study. The purpose of the screening study was to determine the best size, geometry, location and orientation of the micro-ramp actuactors and to set the range of the factor variables which should be studied in the DOE itself. In the screening DOE study, there were actually 5 independent factor (design) variables considered. Using a Main Effects DOE strategy, there were 6 CFD cases run in the screening process. The results of the screening study led to the selection of three factor variables to be included in the current effort and provided the best overall ranges for the selected factor variables.

To test every combination of the three factor variables at the three selected levels, 27 geometries would be needed. DOE techniques were used to select 15 of those cases comprising a face-centered central composite design, which provides the first- and second-order effects of each variable and the firstorder interactions. Within these 15 configurations, three other levels of DOE designs are contained (main effects, D-optimal, and full factorial). 


\section{A. Main Effects Design}

A main effects design for three factor variables contains only four configurations and allows the estimation of the first-order variable effects. The design is termed saturated because all of the data points are used to calculate the response surface coefficients with none left over for error estimation. For the main effects design, the response equation for the incompressible shape factor is

$$
H=a_{0}+a_{1} s+a_{2} h+a_{3} c
$$

where $a_{0}, a_{1}, a_{2}$, and $a_{3}$ are coefficients calculated to fit the measured data points. The equation for the boundary layer thickness has the same form. Main effects designs are useful when very few test cases can be run, only linear responses to the variable are expected with no interaction between variable, or for screening many variables with minimal test cases.

\section{B. D-optimal Design}

The next higher order design is a D-optimal design, which allows for estimation of the first-order effects and chosen first-order variable interactions. Choosing which interactions to include requires some foresight, which in this case was gained by prior CFD calculations. The $s-h$ and $h-c$ interactions were selected, requiring a total of 6 configurations: the four main effects configurations plus two additional ones. A D-optimal design may or may not be saturated depending on which interactions are found to be significant during analysis. If any of the selected interactions proves to not be statistically significant, those terms can be excluded from the model and an error estimate can be made. For the selected D-optimal design, the response equation for the incompressible shape factor is

$$
H=a_{0}+a_{1} s+a_{2} h+a_{3} c+a_{12} s h+a_{23} h c
$$

The equation for the boundary layer thickness has the same form. D-optimal designs are useful to limit the required number of test cases when some information or insight is available to guide the selection of interactions to include in the analysis.

\section{Full Factorial Design}

A full factorial design allows for estimation of the first-order effects and all first-order interactions. A full factorial design is not saturated because there are 8 configurations tested and only 7 coefficients to calculate. Even if all interactions are found to be statistically significant, at least one data point remains for error estimation. For the full factorial design, the response equation for the incompressible shape factor is

$$
H=a_{0}+a_{1} s+a_{2} h+a_{3} c+a_{12} s h+a_{23} h c+a_{13} s c
$$

The equation for the boundary layer thickness has the same form.

\section{Central Composite Design}

All of the 15 configurations taken together comprise a face centered central composite design. This design allows for estimation of first- and second-order effects and all first-order interactions, requiring the estimation of 9 coefficients. For the central composite design, the response equation for the incompressible shape factor is

$$
H=a_{0}+a_{1} s+a_{2} h+a_{3} c+a_{12} s h+a_{23} h c+a_{13} s c+a_{11} s^{2}+a_{22} h^{2}+a_{33} c^{2}
$$

The equation for the boundary layer thickness has the same form. 


\section{Results}

\section{A. Baseline Cases}

Three baseline configurations were tested as part of this effort (1) the tunnel with no microramps and no shock, (2) the tunnel with microramps and no shock, and (3) the tunnel with a shock and no microramps. At each measured x-position for the baseline cases, table 1 gives the span-averaged boundary layer parameters: the boundary layer thickness, $\delta$; the compressible displacement thickness, $\delta^{*}$; the compressible momentum thickness, $\theta$; and the incompressible shape factor, $H$.

The empty tunnel configuration provides information regarding the boundary layer where the microramps were inserted. Figure 8 shows contour plots of the Mach number, M, at the microramp insertion plane $(\mathrm{x}=-13 \mathrm{~cm})$ and the measurement plane $(\mathrm{x}=4 \mathrm{~cm})$. With the Mach 2.0 nozzle block installed in the tunnel, the measured Mach number at the boundary layer edge was $M=1.96$. A row of 11 spanwise static pressure taps was located at $\mathrm{x}=4 \mathrm{~cm}$. For measurements at that position, the wall static pressure used in the Mach number calculation was an average of the nearest taps for points taken when the probe was away from the wall. For profiles at other positions, a single static pressure tap on the tunnel centerline was available at each position for the Mach number calculation.

Figure 9 shows profiles at $\mathrm{x}=-13 \mathrm{~cm}$ and $\mathrm{x}=4 \mathrm{~cm}$ of the velocity ratio, $U / U_{\infty}$, where $U_{\infty}$ is the velocity at the edge of the boundary layer. The data at $\mathrm{x}=-13 \mathrm{~cm}$ shows a boundary layer thickness of $1.14 \mathrm{~cm}$ with the edge of the boundary layer defined at $U / U_{\infty}=0.95$. This gives a microramp height 26.3, 35.0, and 43.7 percent of the boundary layer thickness for the 3, 4, and $5 \mathrm{~mm}$ microramps, respectively. The incompressible shape factor, $H=1.32$, for both positions indicates a typical flat plate turbulent boundary layer. Figure 10 shows how the boundary layer thickness varies in the spanwise direction. The data from the negative $\mathrm{z}$ locations is plotted as the absolute value of the $\mathrm{z}$ coordinate and indicated by the red crosses. This was done to make any asymmetries in the flow easier to identify.

For the configuration with microramps and no shock the microramp insert with microramps of $s=25 \mathrm{~mm}, h=3 \mathrm{~mm}$, and $c=12 \mathrm{~mm}$ was tested. This configuration provides insight into the development of the vortices. Figure 11 shows contour plots of the Mach number, M, at planes $\mathrm{x}=-8,-4,0$, and $4 \mathrm{~cm}$. Moving downstream, the region of influence of the vortex rises. Figure 12 shows the velocity ratio profile at $\mathrm{z}=0 \mathrm{~cm}$ for the same four $\mathrm{x}$-planes downstream of the microramps. Figure 13 shows how the boundary layer thickness varies in the spanwise direction. As the vortex develops, the boundary layer is thicker in line with the microramp tip $(\mathrm{z}=0 \mathrm{~cm})$ and thins in the region between the ramps.

The Mach number contours for the configuration with the oblique shock and no microramps are shown in figure 14 and provide a direct comparison to the results that will be shown in the following section. Downstream of the reflected shock the edge Mach number is reduced to $M=1.43$. The velocity ratio profile at $\mathrm{z}=0 \mathrm{~cm}$ is shown in figure 15 . At the $\mathrm{x}=4 \mathrm{~cm}$ measurement plane the shock increases the boundary layer thickness to $1.40 \mathrm{~cm}$ compared to $1.30 \mathrm{~cm}$ for the baseline with no shock. Also, the incompressible shape factor increases to $H=1.75$ compared to $H=1.32$ for the no shock case. Figure 16 shows how the boundary layer thickness varies in the spanwise direction for the oblique shock case.

\section{B. DOE Response}

Response surfaces were created to model the variation of the boundary layer thickness and incompressible shape factor within the design space. The span-averaged boundary layer parameters for all configurations used in the analysis are shown in table 2 . Coefficients were calculated based on each of the four orders of design described in section III. The resulting coefficients are shown in tables 3 and 4 for the boundary layer thickness and incompressible shape factor, respectively. Any coefficients not listed in the table were zero for all designs. 
Figures 17 to 24 show contours for these equations on planes at the edge of the design space. The results for the main effects (figs. 17 and 18) and D-optimal (figs. 19 and 20) designs are very similar. The effects of the interactions and second-order terms can be seen in the full factorial (figs. 21 and 22) and central composite (figs. 23 and 24), respectively. The second-order effects are particularly evident in the curved boundary layer thickness contours in figure 23. Comparing the boundary layer thickness and incompressible shape factor, the quantities minimize in opposite corners of the design space.

The result of using each of the design orders to compute an optimal microramp configuration based on minimizing the incompressible shape factor is shown in table 5. For each of the cases, the minimum occurs at or near $s=25 \mathrm{~mm}, h=5 \mathrm{~mm}, c=24 \mathrm{~mm}$. The minimum values for incompressible shape factor agree for all orders of design. Note that the value for the main effects experiment is exactly the measured value at that point. This is expected, since four points are used to calculate four coefficients. The last two columns of the table show the range of the 95 percent confidence interval, which indicates the range in which the true value of the incompressible shape factor is expected to fall. For the main effects design, no calculation on the confidence interval can be made because the design is saturated. Increasing the number of available data points decreases the range of the confidence interval indicating a more accurate estimation of the value.

\section{Microramp Configurations}

For each of the 15 microramp configurations tested, the Mach number contours downstream of the shock reflection are shown in figure 25 . Increasing the height or chord length creates a stronger vortex that has influence extending farther into the core flow. This agrees with the DOE response surface showing increased boundary layer thickness for microramps with a large height and chord compared to smaller microramps. Figure 26 shows the contours of $\mathrm{M}-\mathrm{M}_{\mathrm{b}}$, where $\mathrm{M}_{\mathrm{b}}$ is $\mathrm{Mach}$ number for the baseline oblique shock only case, similar to figures shown for previous microramp research (ref. 6). This emphasizes the changes in the flow caused by the microramps. The $\mathrm{M}-\mathrm{M}_{\mathrm{b}}=0$ contours are marked in the figure. In these plots the velocity deficit caused by the microramp is apparent. The magnitude of the deficit increases with increasing height and chord, as the stronger vortices carry more of the higher momentum fluid near the wall. This increased mixing accounts for the improvements in incompressible shape factor for large microramps. Even though the velocity deficit increases, the corresponding increases in the near wall velocity outweigh this effect in the calculation of the shape factor. Figure 27 shows how the boundary layer thickness varies in the spanwise direction. As was true for the microramp configuration without the shock, for these cases the boundary layer is thicker in line with the microramp tip and thins in the region between the ramps. Comparing the points for positive and negative z-positions, the symmetry was generally quite good.

\section{Conclusion}

Design of experiments techniques are well suited to evaluating the effectiveness of microramps. The response surface equation for microramps is expected to be continuous. DOE also allows the many potential variables to study to be dealt with efficiently in a controlled manner. Different orders of DOE designs provide different benefits for microramp evaluation. The main effects design allows very few data points to be used to estimate the response surface, but no error estimate is available. Using a main effects design, the optimal configuration based on a single variable optimization will always occur in the corner of the design space due to the form of the response equation. For the variables and ranges in the current study, the main effects design was found to provide a reasonable estimate of the response variable trends. The D-optimal design still requires very few configurations and can have points for error estimation if not all chosen interactions are statistically significant. The range of the confidence interval is fairly large for the D-optimal design, but may be sufficient for some purposes. The factorial design required twice the points of a main effects design, but greatly improves the confidence interval. For evaluation of microramp configurations, the factorial design provides a balance of accuracy and test efficiency that makes it a 
promising model for configuration specific design. The central composite design requires a significantly larger test matrix for minimal improvement of the estimates of the response variables in this study. For other variables or ranges where second order effects are important, moving to a central composite design may be necessary in order to accurately predict the effects of the factor variables.

The optimum value for shape factor according to each of the orders of DOE designs occurs for ramps with a large height and chord length and a close spacing relative to the design space. The minimum boundary layer thickness occurs at the opposite of all three geometric parameters. Looking at the flowfield measured downstream of the oblique shock reflection, microramps with small heights and chord lengths generate relatively weak vortices. Most of the mixing in this case occurs within the boundary layer, allowing minimal increase in boundary layer thickness, but providing little benefit to the near wall flow. For larger microramps with stronger vortices, more flow is pulled into the near wall region, including part of the core flow. This provides a greater benefit to the near wall flow leading to improvements in incompressible shape factor. For an inlet system, a combination of these and potentially additional parameters such as wall shear stress will likely need to be considered together to determine the optimal configuration of microramps for a given system. Work is currently planned that will look at the effects of microramps in a system with shocks and a subsonic diffuser to help answer the question at a system level.

\section{References}

1. Anderson B.H., Tinapple, J., Surber, L., "Optimal Control of Shock Wave Turbulent Boundary Layer Interactions Using Micro-Array Actuation,” AIAA-2006-3197, June 2006.

2. Lin J.C., "Review of Research on Low-Profile Vortex Generators to Control Boundary-Layer Separation," Progress in Aerospace Sciences, 2002.

3. Box, G.E.P., Hunter, W.G., and Hunter, J.S., "Statistics for Experimenters," John Wiley, New York.

4. Fukuda, M.K., Hingst, W.G., Reshotko, E., "Control of Shock Wave-Boundary Layer Interactions by Bleed in Supersonic Mixed Compression Inlets," NASA CR-2595, 1975.

5. Castillo, L., Wang, X., George, W.K., "Separation Criterion for Turbulent Boundary Layers Via Similarity Analysis," Journal of Fluids Engineering, vol. 126, p. 297, 2004.

6. Ford, C.W.P., Babinsky, H., "Micro-Ramp Control for Oblique Shock Wave/Boundary Layer Interactions," AIAA-2007-4115, June 2007.

TABLE 1.-SPAN-AVERAGED BOUNDARY LAYER PARAMETERS FOR BASELINE CONFIGURATIONS

\begin{tabular}{|l|c|c|c|c|c|}
\hline \multicolumn{2}{|c|}{} & $\begin{array}{c}\delta, \\
\mathrm{cm}\end{array}$ & $\begin{array}{c}\delta^{*}, \\
\mathrm{~cm}\end{array}$ & $\begin{array}{c}\theta, \\
\mathrm{cm}\end{array}$ & $H$ \\
\hline $\mathrm{x}=-13 \mathrm{~cm}$ & none & 1.142 & 0.283 & 0.100 & 1.316 \\
\hline \multirow{3}{*}{$\mathrm{x}=-8 \mathrm{~cm}$} & none & 1.196 & 0.292 & 0.104 & 1.314 \\
\cline { 2 - 6 } & microramps & 1.188 & 0.291 & 0.117 & 1.338 \\
\hline \multirow{3}{*}{$\mathrm{x}=-4 \mathrm{~cm}$} & none & 1.217 & 0.301 & 0.106 & 1.321 \\
\cline { 2 - 6 } & microramps & 1.325 & 0.324 & 0.108 & 1.303 \\
\hline \multirow{3}{*}{$\mathrm{x}=0 \mathrm{~cm}$} & none & 1.350 & 0.342 & 0.116 & 1.303 \\
\hline \multirow{3}{*}{$\mathrm{x}=4 \mathrm{~cm}$} & microramps & 1.358 & 0.347 & 0.120 & 1.297 \\
\cline { 2 - 6 } & none & 1.297 & 0.326 & 0.118 & 1.322 \\
\cline { 2 - 6 } & microramps & 1.333 & 0.337 & 0.124 & 1.322 \\
\cline { 2 - 6 } & shock & 1.402 & 0.516 & 0.190 & 1.746 \\
\hline
\end{tabular}


TABLE 2.-SPAN-AVERAGED BOUNDARY LAYER PARAMETERS AT $\mathrm{x}=4 \mathrm{~cm}$ FOR ALL CONFIGURATIONS

\begin{tabular}{|c|c|c|c|c|c|c|}
\hline $\begin{array}{c}s, \\
\mathrm{~mm}\end{array}$ & $\begin{array}{c}h, \\
\mathrm{~mm}\end{array}$ & $\begin{array}{c}c, \\
\mathrm{~mm}\end{array}$ & $\begin{array}{c}\delta, \\
\mathrm{cm}\end{array}$ & $\begin{array}{c}\delta^{*}, \\
\mathrm{~cm}\end{array}$ & $\begin{array}{c}\theta, \\
\mathrm{cm}\end{array}$ & $H$ \\
\hline 25 & 3 & 12 & 1.438 & 0.527 & 0.197 & 1.724 \\
\hline 35 & 3 & 12 & 1.448 & 0.530 & 0.196 & 1.731 \\
\hline 25 & 5 & 12 & 1.651 & 0.552 & 0.213 & 1.666 \\
\hline 35 & 5 & 12 & 1.587 & 0.538 & 0.206 & 1.679 \\
\hline 25 & 3 & 24 & 1.522 & 0.537 & 0.205 & 1.690 \\
\hline 35 & 3 & 24 & 1.498 & 0.531 & 0.201 & 1.701 \\
\hline 25 & 5 & 24 & 1.726 & 0.556 & 0.226 & 1.617 \\
\hline 35 & 5 & 24 & 1.665 & 0.545 & 0.217 & 1.631 \\
\hline 25 & 4 & 18 & 1.602 & 0.538 & 0.210 & 1.639 \\
\hline 35 & 4 & 18 & 1.538 & 0.526 & 0.202 & 1.663 \\
\hline 30 & 3 & 18 & 1.452 & 0.530 & 0.198 & 1.720 \\
\hline 30 & 5 & 18 & 1.548 & 0.509 & 0.204 & 1.627 \\
\hline 30 & 4 & 12 & 1.511 & 0.527 & 0.200 & 1.678 \\
\hline 30 & 4 & 24 & 1.590 & 0.535 & 0.209 & 1.644 \\
\hline 30 & 4 & 18 & 1.571 & 0.528 & 0.204 & 1.653 \\
\hline
\end{tabular}

TABLE 3.-DOE MODEL COEFFICIENTS FOR BOUNDARY LAYER THICKNESS, $\delta$

\begin{tabular}{|c|c|c|c|c|c|c|}
\hline & $a_{0}$ & $a_{1}$ & $a_{2}$ & $a_{3}$ & $a_{12}$ & $a_{11}$ \\
\hline Main effects & $1.156 \mathrm{E}+00$ & $-4.010 \mathrm{E}-03$ & $9.440 \mathrm{E}-02$ & $8.275 \mathrm{E}-03$ & ------------- & ------------- \\
\hline D-optimal & $1.201 \mathrm{E}+00$ & $-3.298 \mathrm{E}-03$ & $8.549 \mathrm{E}-02$ & $6.790 \mathrm{E}-03$ & $0.000 \mathrm{E}+00$ & ---- \\
\hline Factorial & $8.696 \mathrm{E}-01$ & $7.603 \mathrm{E}-03$ & $1.736 \mathrm{E}-01$ & $5.965 \mathrm{E}-03$ & $-2.773 \mathrm{E}-03$ & |------------ \\
\hline Central composite & $2.412 \mathrm{E}+00$ & $-8.358 \mathrm{E}-02$ & $8.187 \mathrm{E}-02$ & $6.087 \mathrm{E}-03$ & $0.000 \mathrm{E}+00$ & $1.325 \mathrm{E}-03$ \\
\hline
\end{tabular}

TABLE 4.-DOE MODEL COEFFICIENTS FOR INCOMPRESSIBLE SHAPE FACTOR, $H$

\begin{tabular}{|l|c|c|c|c|c|c|}
\hline & $a_{0}$ & $a_{1}$ & $a_{2}$ & $a_{3}$ & $a_{23}$ & $a_{22}$ \\
\hline Main effects & $1.815 \mathrm{E}+00$ & $1.935 \mathrm{E}-03$ & $-3.223 \mathrm{E}-02$ & $-3.538 \mathrm{E}-03$ & ------------ & ----------- \\
\hline D-optimal & $1.819 \mathrm{E}+00$ & $1.500 \mathrm{E}-03$ & $-3.129 \mathrm{E}-02$ & $-3.381 \mathrm{E}-03$ & $0.000 \mathrm{E}+00$ & ------------ \\
\hline Factorial & $1.784 \mathrm{E}+00$ & $1.128 \mathrm{E}-03$ & $-1.948 \mathrm{E}-02$ & $-6.396 \mathrm{E}-04$ & $-6.729 \mathrm{E}-04$ & ------------ \\
\hline Central composite & $2.179 \mathrm{E}+00$ & $1.384 \mathrm{E}-03$ & $-2.187 \mathrm{E}-01$ & $-3.240 \mathrm{E}-03$ & $0.000 \mathrm{E}+00$ & $2.301 \mathrm{E}-02$ \\
\hline
\end{tabular}

TABLE 5.-OPTIMIZATION RESULTS FOR THE FOUR LEVELS OF DOE DESIGNS

\begin{tabular}{|l|c|c|c|c|c|c|}
\hline & $\begin{array}{c}s, \\
\mathrm{~mm}\end{array}$ & $\begin{array}{c}h, \\
\mathrm{~mm}\end{array}$ & $\begin{array}{c}c, \\
\mathrm{~mm}\end{array}$ & $\begin{array}{c}H_{\text {min }} \\
\text { Main effects }\end{array}$ & $\begin{array}{c}95 \text { percent } \\
\text { CI low }\end{array}$ & $\begin{array}{c}95 \text { percent } \\
\text { CI high }\end{array}$ \\
\hline D-optimal & 25 & 5 & 24 & 1.617 & ----- & ---- \\
\hline Factorial & 25 & 5 & 24 & 1.61888 & 1.59 & 1.64 \\
\hline Central composite & 25.51 & 4.72 & 23.99 & 1.61688 & 1.61 & 1.62 \\
\hline
\end{tabular}




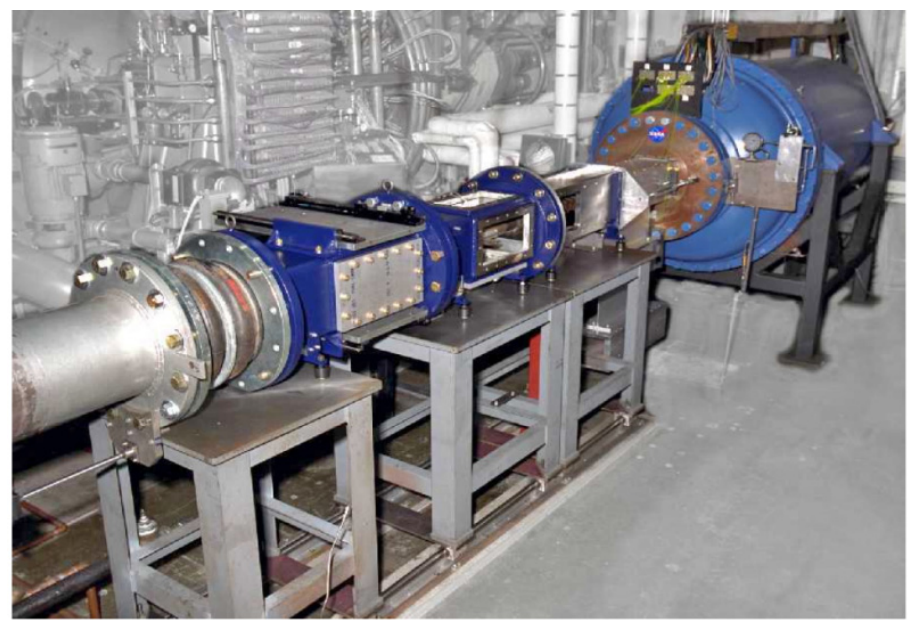

Figure 1.-The 15- by 15-Centimeter Supersonic Wind Tunnel at NASA Glenn Research Center.

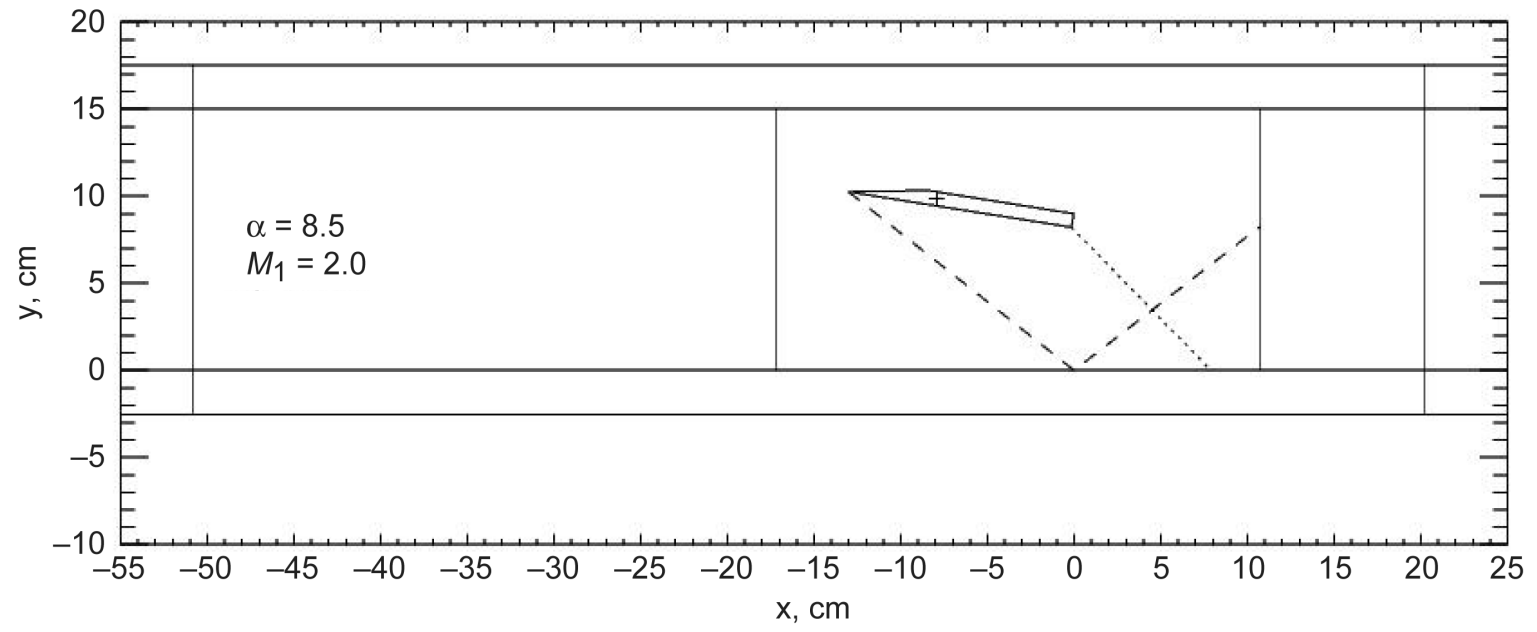

Figure 2.-Layout of the test in the tunnel. Microramp centerline was positioned at $x=-13 \mathrm{~cm}$. 

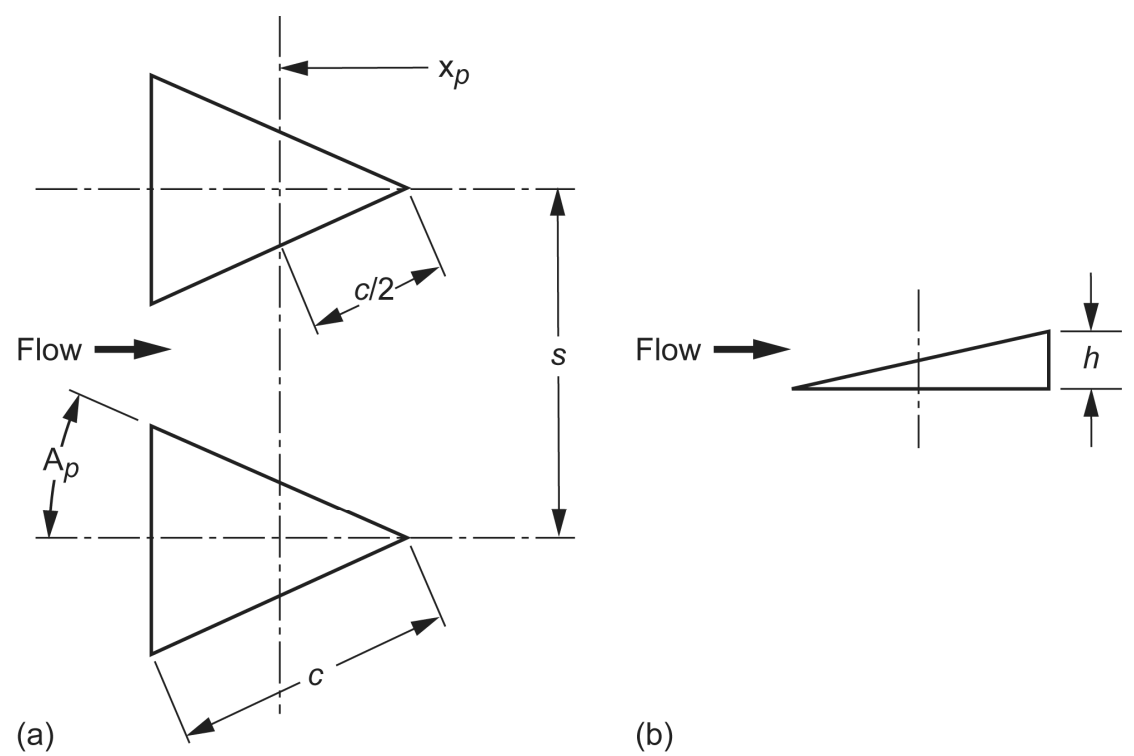

Figure 3.-Microramp geometry parameters shown in views. (a) A top view. (b) A side view.

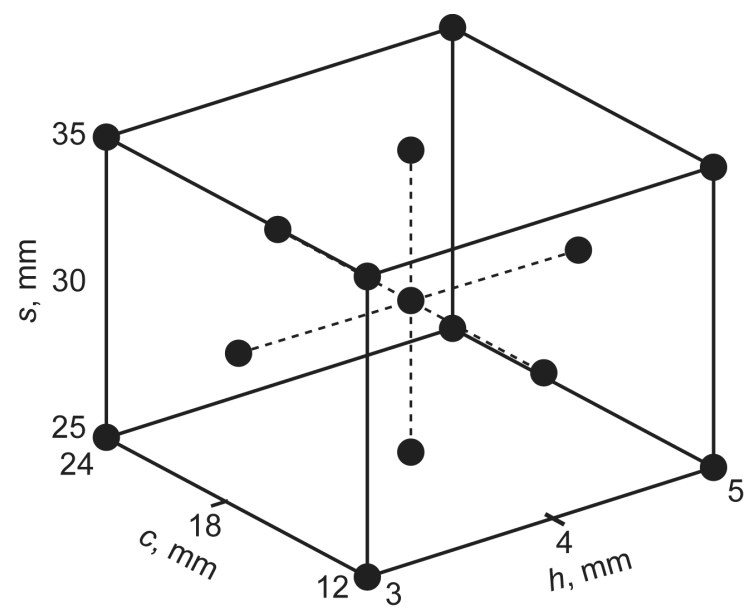

Figure 4.-Face-centered central composite DOE design. The circles indicate variable combinations that were tested.

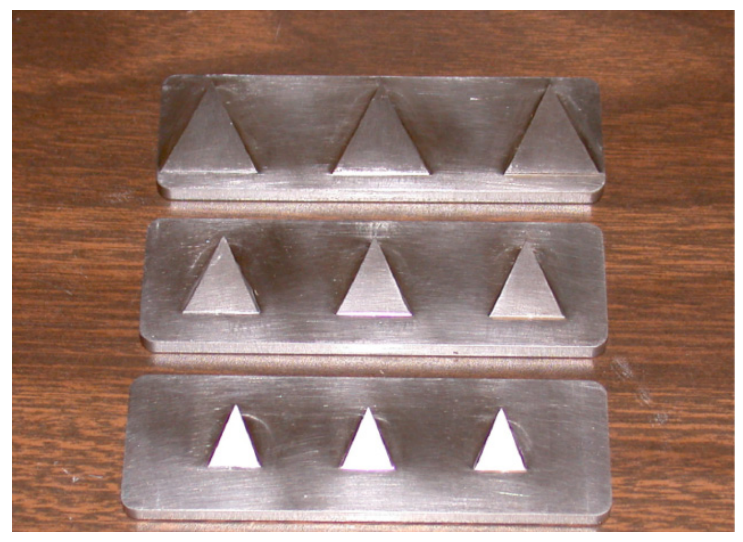

Figure 5.-Picture of three microramp inserts. 


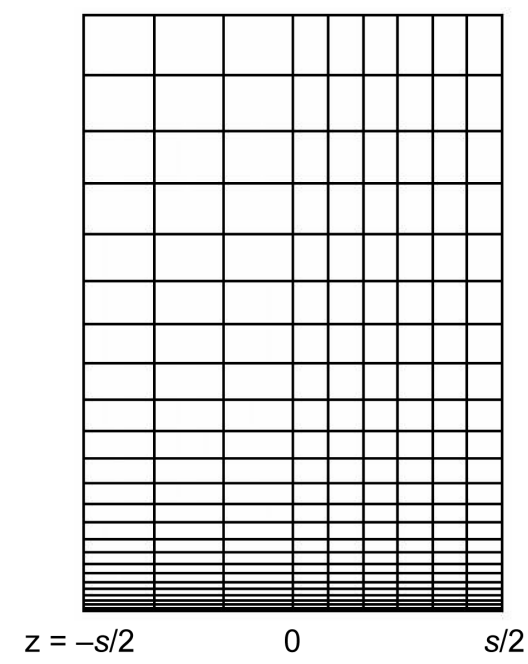

Figure 6.-Representation of the measurement plane. Each intersection represents a measurement point.

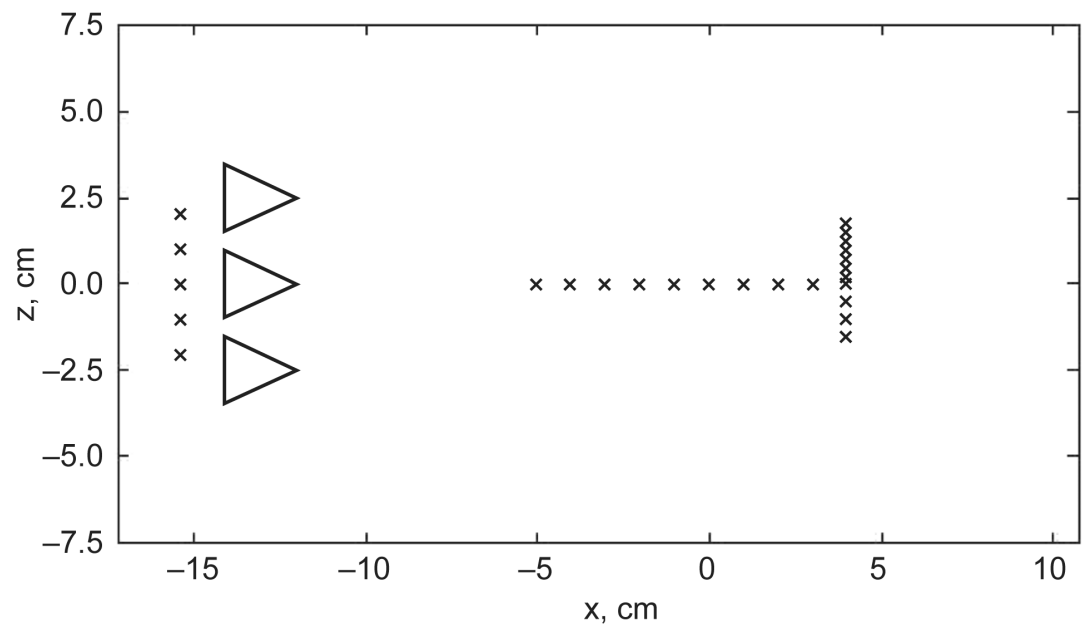

Figure 7.-Static pressure tap distribution with tap locations marked by " $\mathrm{x}$ ".
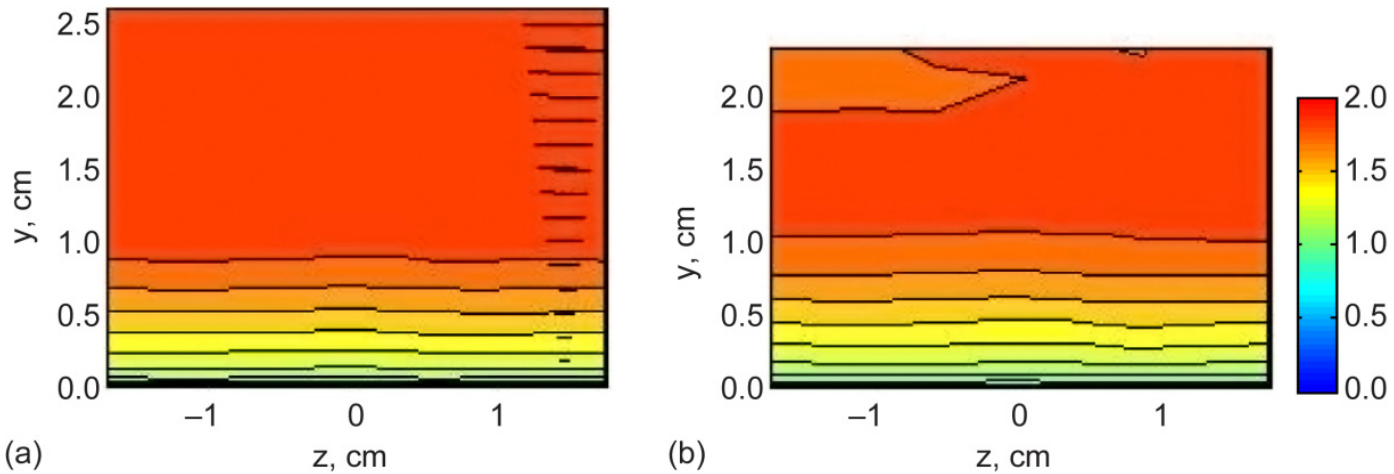

Figure 8.-Contour plots of Mach number, $\mathrm{M}$, for the case with no shock and no microramps.

(a) $x=-13 \mathrm{~cm}$. (b) $x=4 \mathrm{~cm}$. 

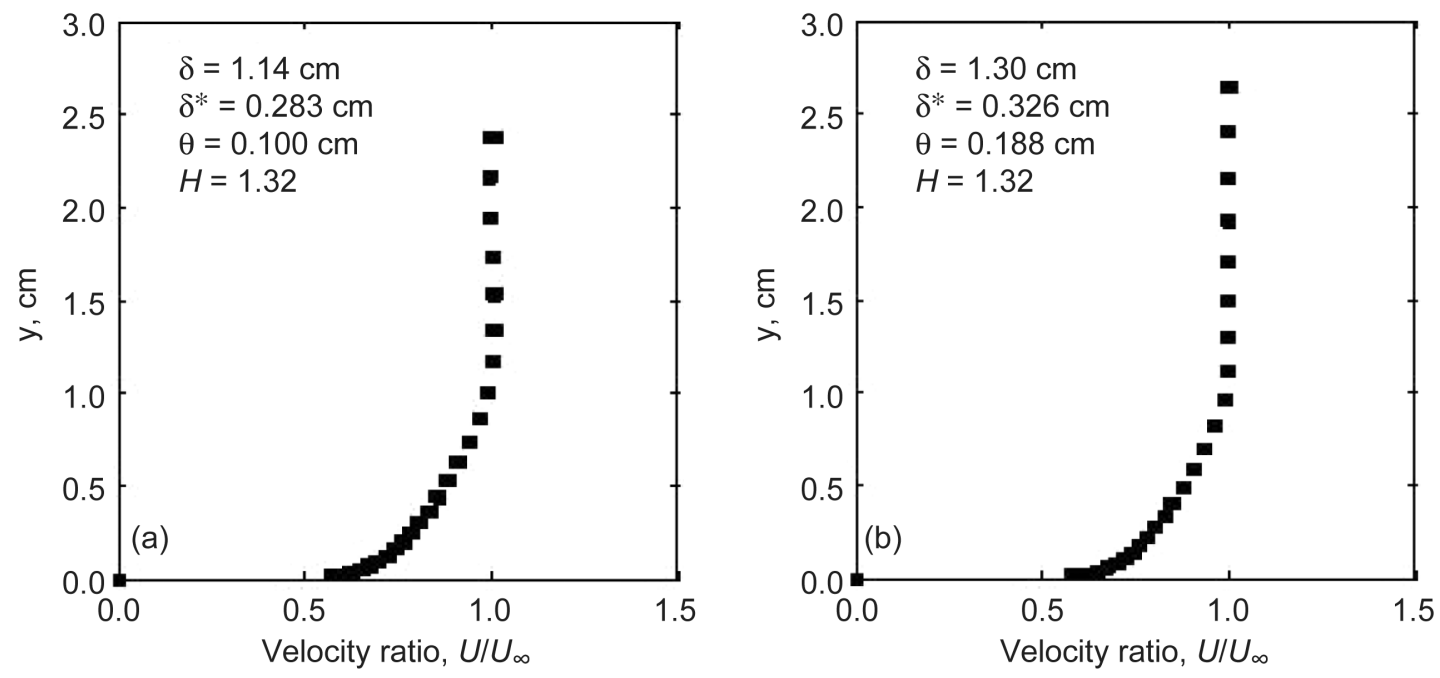

Figure 9.-Profiles of the velocity ratio, $U / U_{\infty}$, on the tunnel centerline for the case with no shock and no microramps. (a) $x=-13 \mathrm{~cm}$. (b) $x=4 \mathrm{~cm}$.
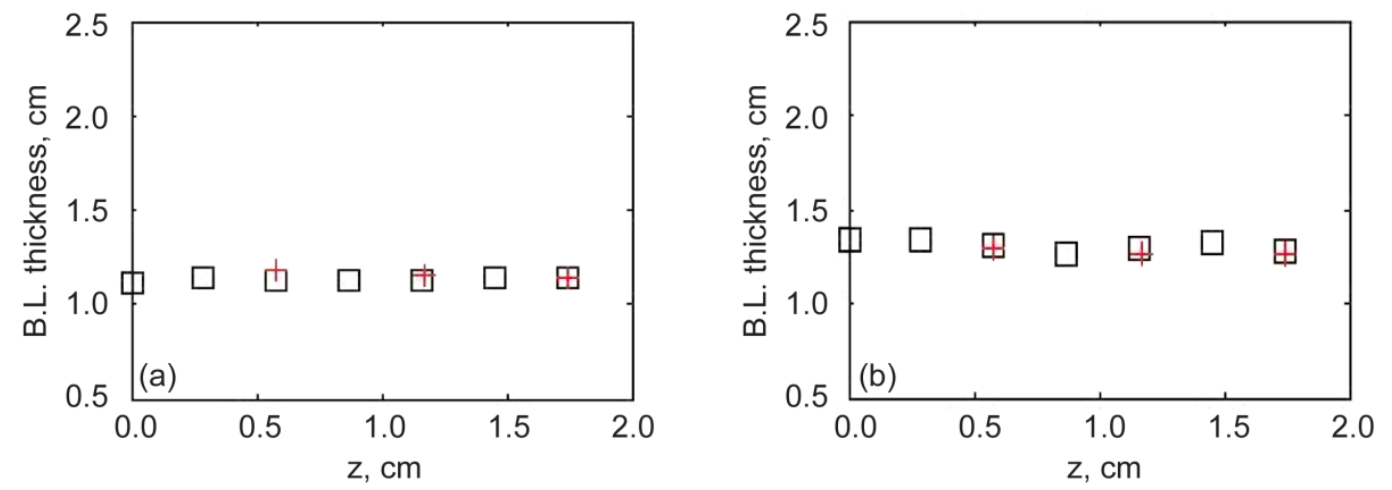

Figure 10.-Spanwise boundary layer thickness, $\delta$, variation with negative $z$ values mirrored across the $y$-axis for the case with no shock and no microramps. (a) $x=-13 \mathrm{~cm}$. (b) $x=4 \mathrm{~cm}$. 

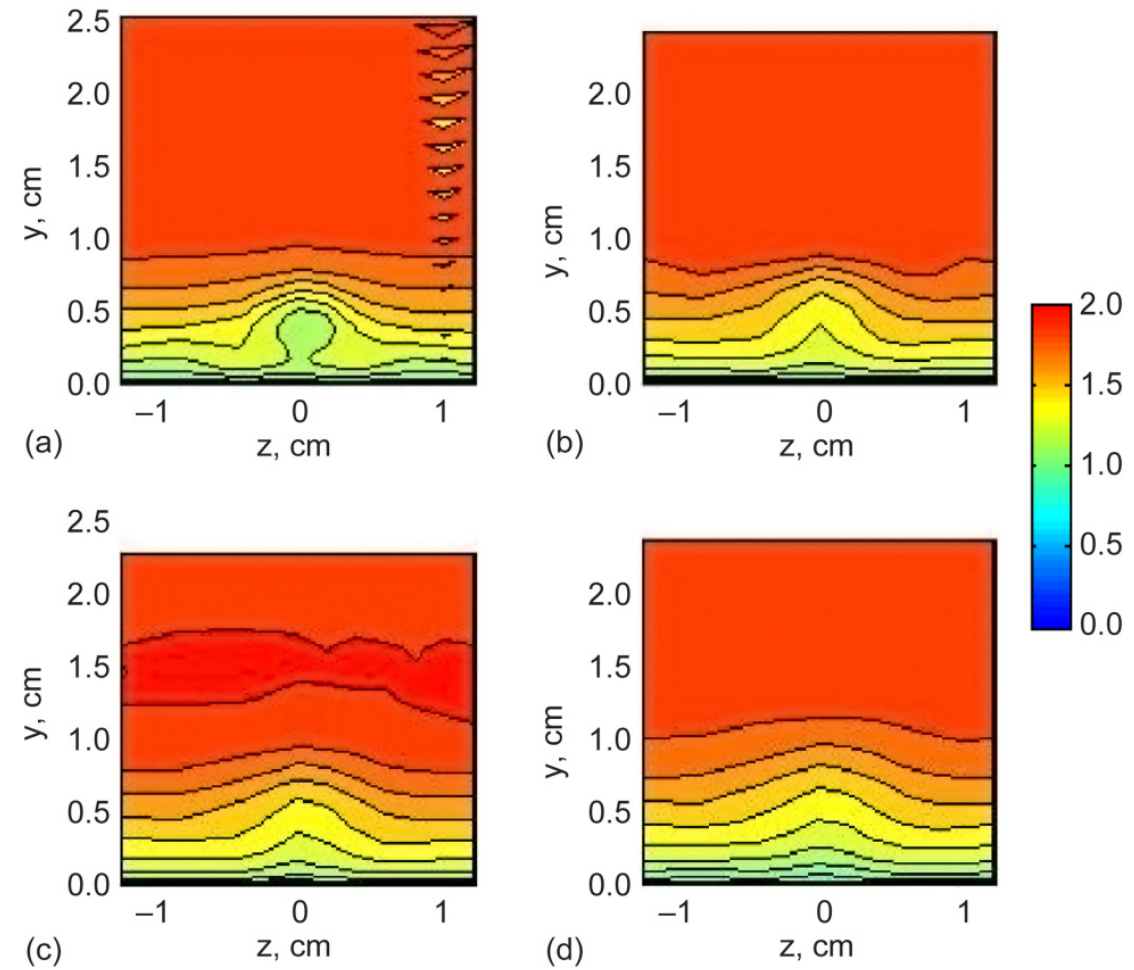

(c)

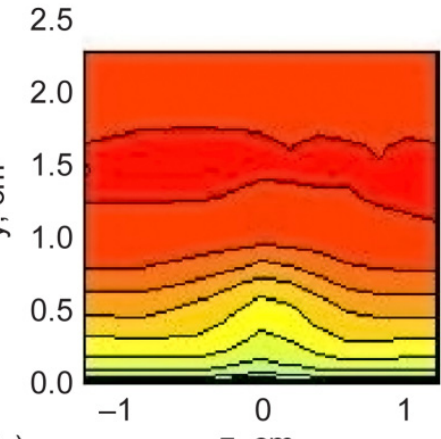

Figure 11.-Contour plots of Mach number, $\mathrm{M}$, for the case with no shock and baseline microramps. (a) $x=-8 \mathrm{~cm}$. (b) $x=-4 \mathrm{~cm}$. (c) $x=0 \mathrm{~cm}$. (d) $x=4 \mathrm{~cm}$. 

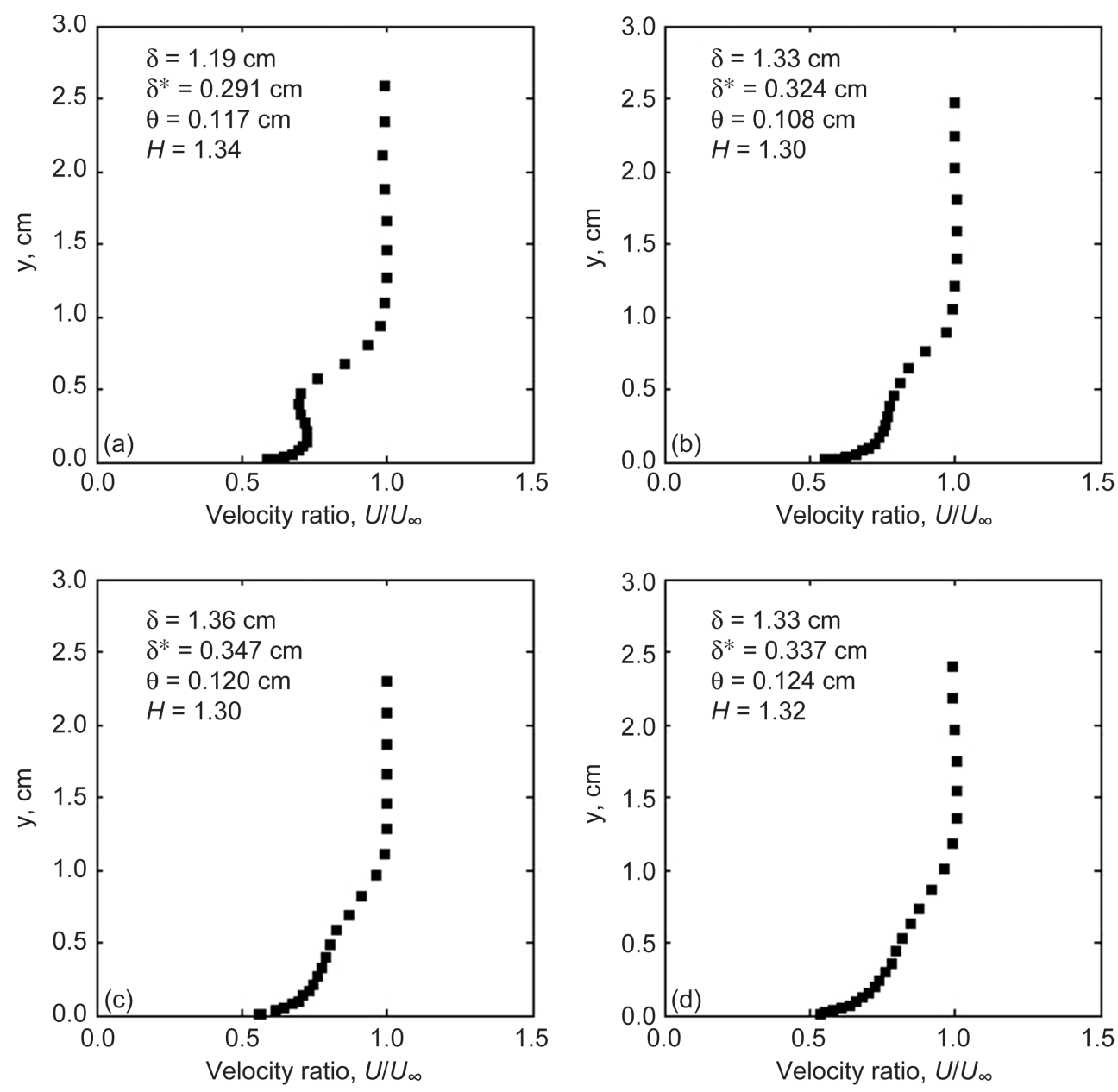

Figure 12.-Profiles of the velocity ratio, $U / U_{\infty}$, on the tunnel centerline for the case with no shock and baseline microramps. (a) $x=-8 \mathrm{~cm}$. (b) $x=-4 \mathrm{~cm}$. (c) $x=0 \mathrm{~cm}$. (d) $x=4 \mathrm{~cm}$. 

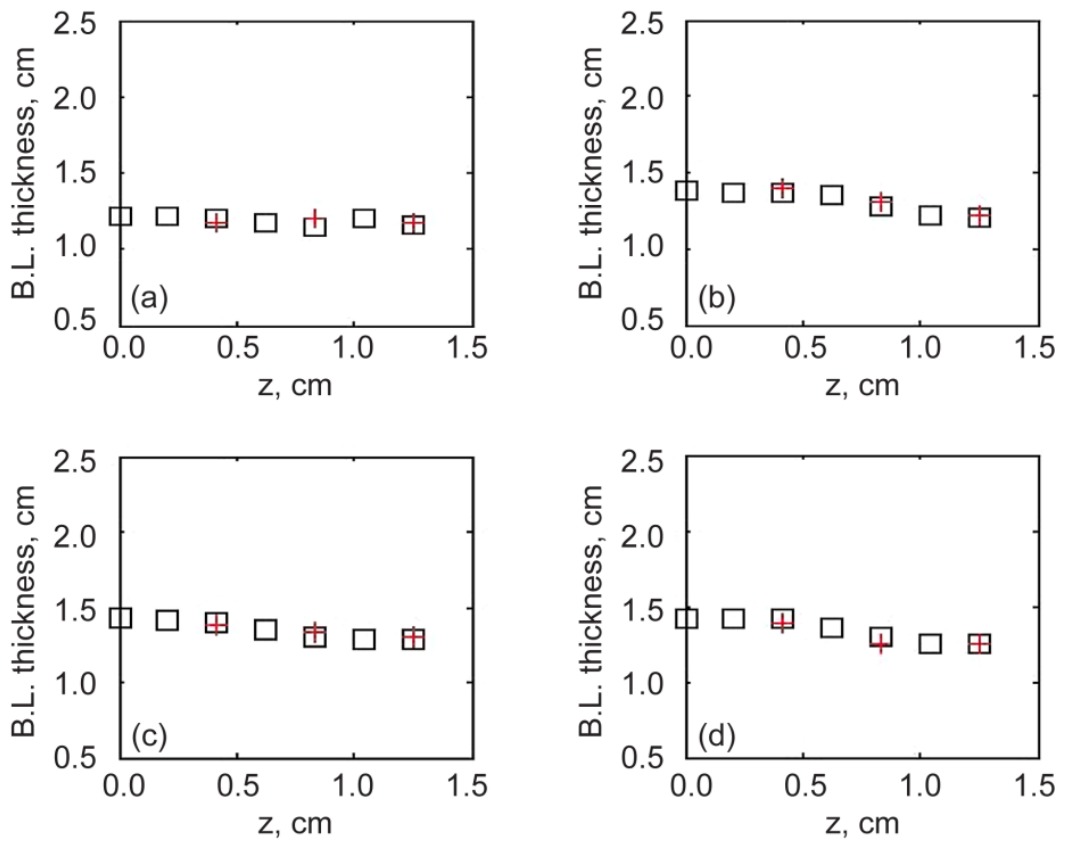

Figure 13.-Spanwise boundary layer thickness, $\delta$, variation with negative $z$ values mirrored across the $y$-axis for the case with no shock and baseline microramps. (a) $x=-8 \mathrm{~cm}$. (b) $x=-4 \mathrm{~cm}$. (c) $x=0 \mathrm{~cm}$. (d) $x=4 \mathrm{~cm}$.

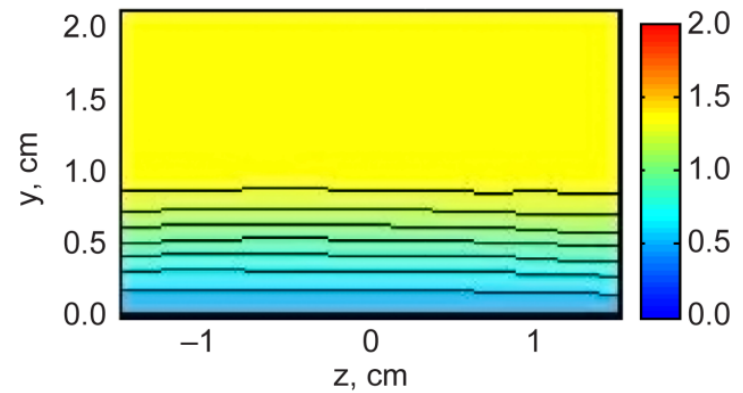

Figure 14.-Contour plots of Mach number, $\mathrm{M}$, for the case with an oblique shock and no microramps at $x=4 \mathrm{~cm}$. 


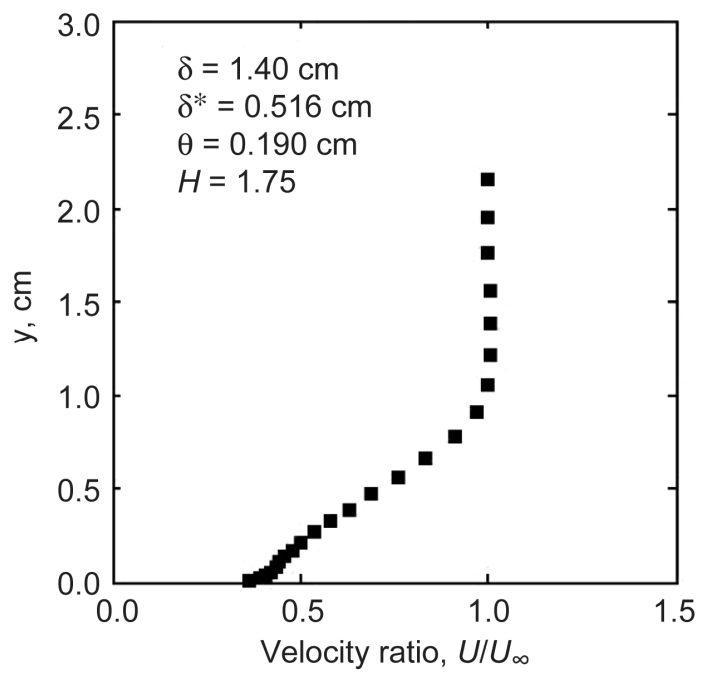

Figure 15.-Profiles of the velocity ratio, $U / U_{\infty}$, on the tunnel centerline for the case with an oblique shock and no microramps at $\mathrm{x}=4 \mathrm{~cm}$.

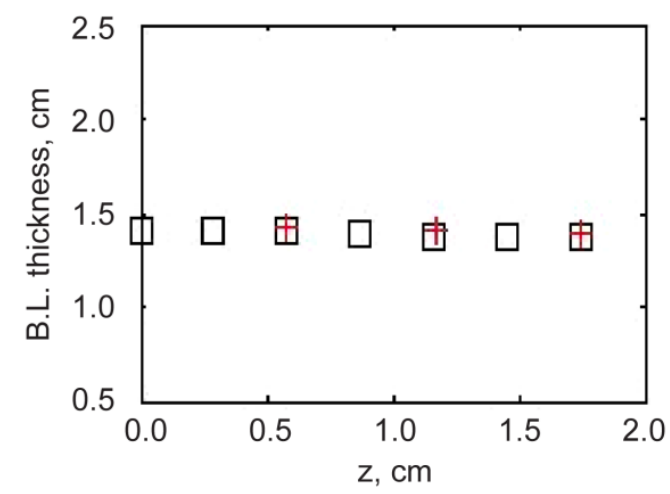

Figure 16.-Spanwise boundary layer thickness, $\delta$, variation with negative $z$ values mirrored across the $y$-axis for the case with an oblique shock and no microramps at $x=4 \mathrm{~cm}$.
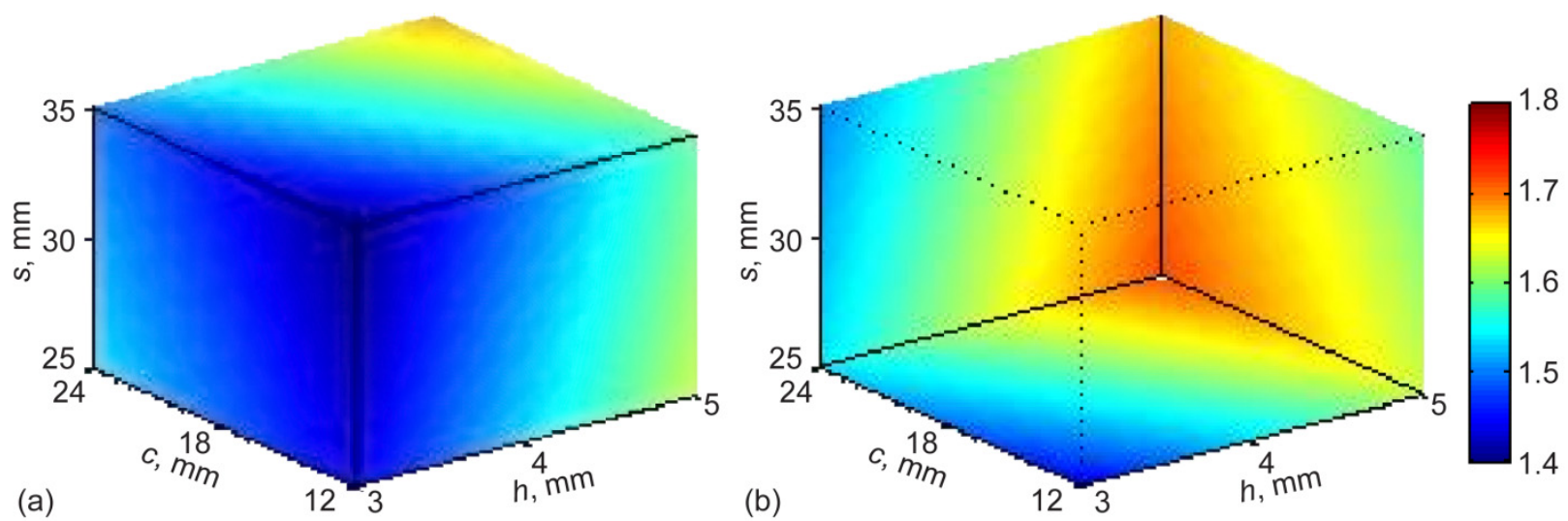

Figure 17.-Main effects DOE model for boundary layer thickness, $\delta$. Levels of $\delta$ are shown as contours. (a) $s=35 \mathrm{~mm}, h=3 \mathrm{~mm}$, and $c=12 \mathrm{~mm}$ surfaces. (b) $s=25 \mathrm{~mm}, h=5 \mathrm{~mm}$, and $c=24 \mathrm{~mm}$ surfaces. 

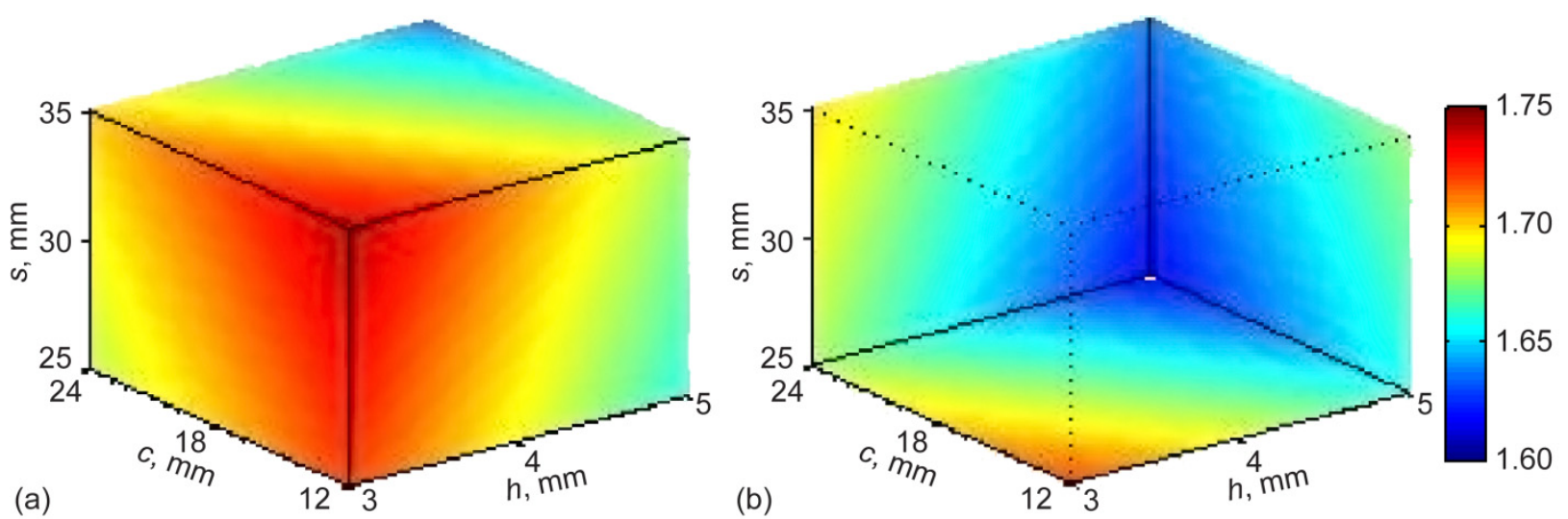

Figure 18.-Main effects DOE model for incompressible shape factor, $H$. Levels of $H$ are shown as contours. (a) $s=35 \mathrm{~mm}, h=3 \mathrm{~mm}$, and $c=12 \mathrm{~mm}$ surfaces. (b) $s=25 \mathrm{~mm}, h=5 \mathrm{~mm}$, and $c=24 \mathrm{~mm}$ surfaces.
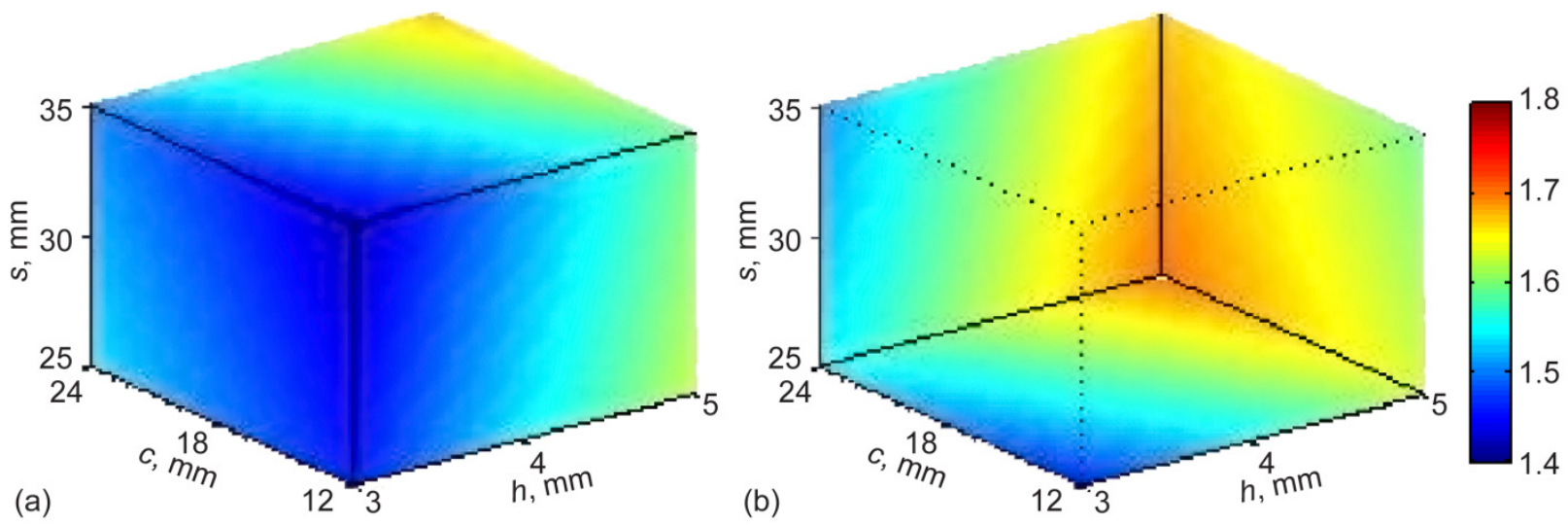

Figure 19.-D-optimal DOE model for boundary layer thickness, $\delta$. Levels of $\delta$ are shown as contours.

(a) $s=35 \mathrm{~mm}, h=3 \mathrm{~mm}$, and $c=12 \mathrm{~mm}$ surfaces. (b) $s=25 \mathrm{~mm}, h=5 \mathrm{~mm}$, and $c=24 \mathrm{~mm}$ surfaces.
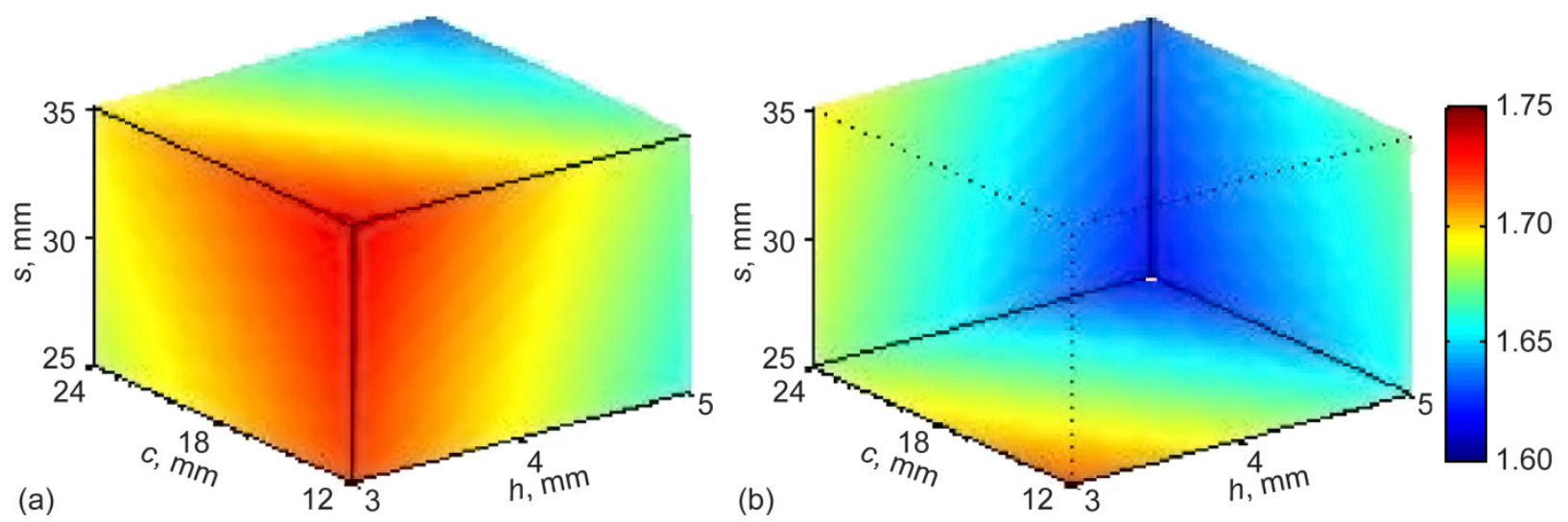

Figure 20.-D-optimal DOE model for incompressible shape factor, $H$. Levels of $H$ are shown as contours. (a) $s=35 \mathrm{~mm}, h=3 \mathrm{~mm}$, and $c=12 \mathrm{~mm}$ surfaces. (b) $s=25 \mathrm{~mm}, h=5 \mathrm{~mm}$, and $c=24 \mathrm{~mm}$ surfaces. 

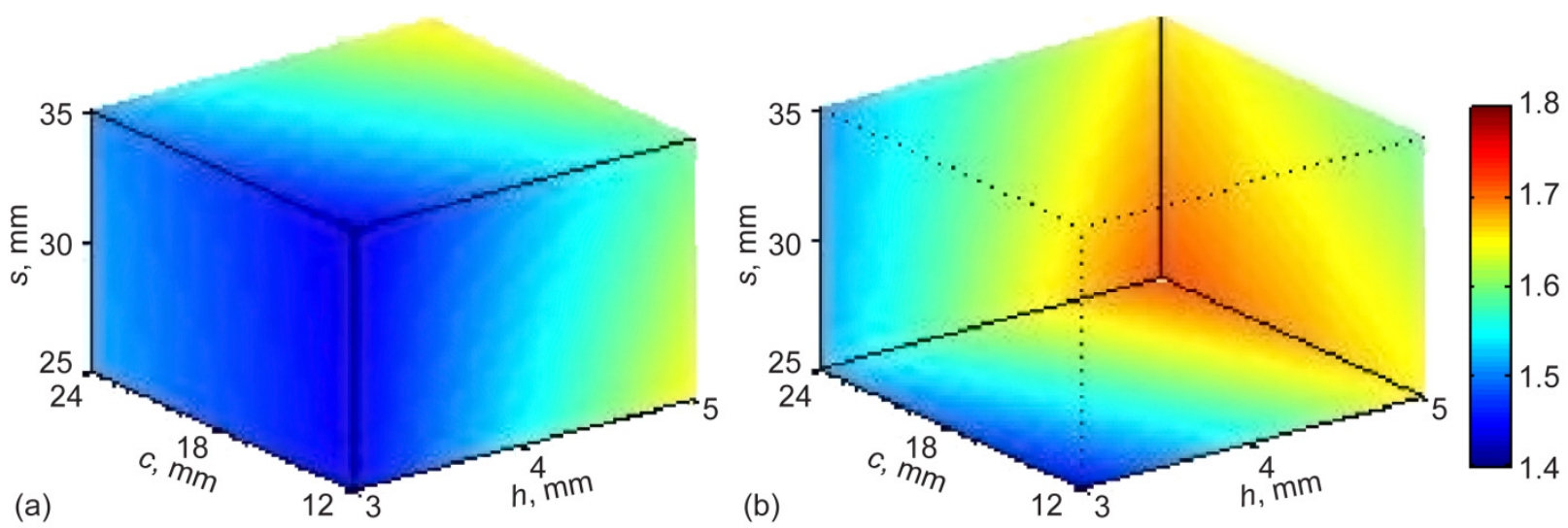

Figure 21.-Full Factorial DOE model for boundary layer thickness, $\delta$. Levels of $\delta$ are shown as contours.

(a) $s=35 \mathrm{~mm}, h=3 \mathrm{~mm}$, and $c=12 \mathrm{~mm}$ surfaces. (b) $s=25 \mathrm{~mm}, h=5 \mathrm{~mm}$, and $c=24 \mathrm{~mm}$ surfaces.
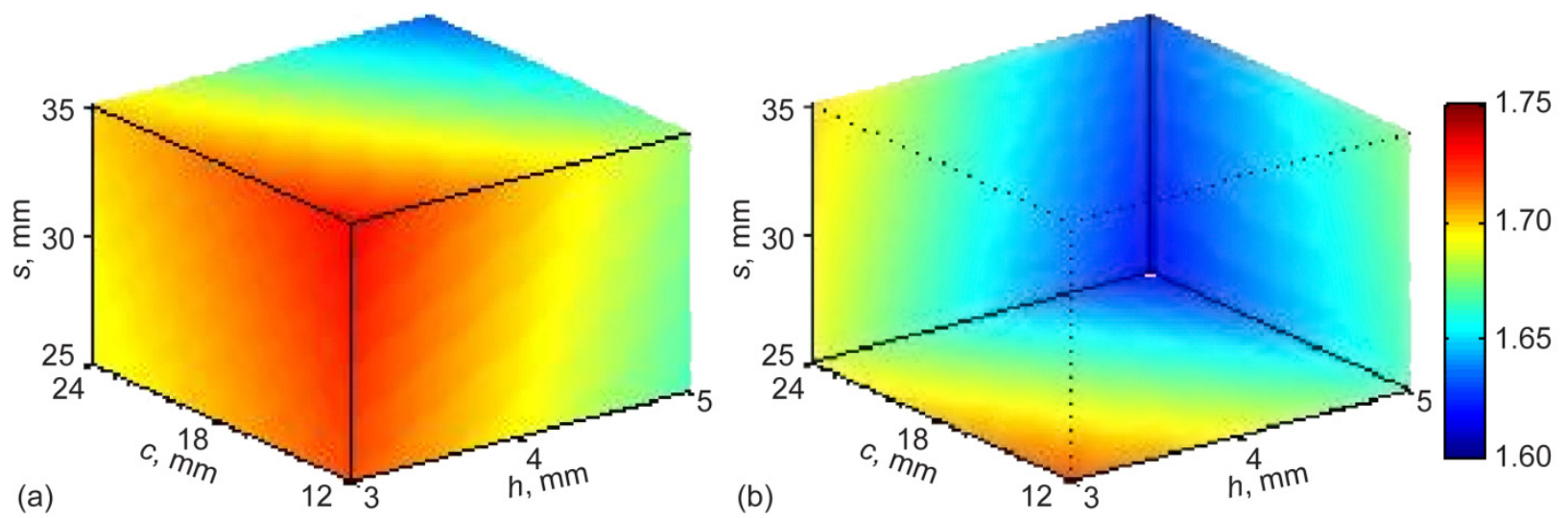

Figure 22.-Full factorial DOE model for incompressible shape factor, $H$. Levels of $H$ are shown as contours. (a) $s=35 \mathrm{~mm}, h=3 \mathrm{~mm}$, and $c=12 \mathrm{~mm}$ surfaces. (b) $s=25 \mathrm{~mm}, h=5 \mathrm{~mm}$, and $c=24 \mathrm{~mm}$ surfaces.
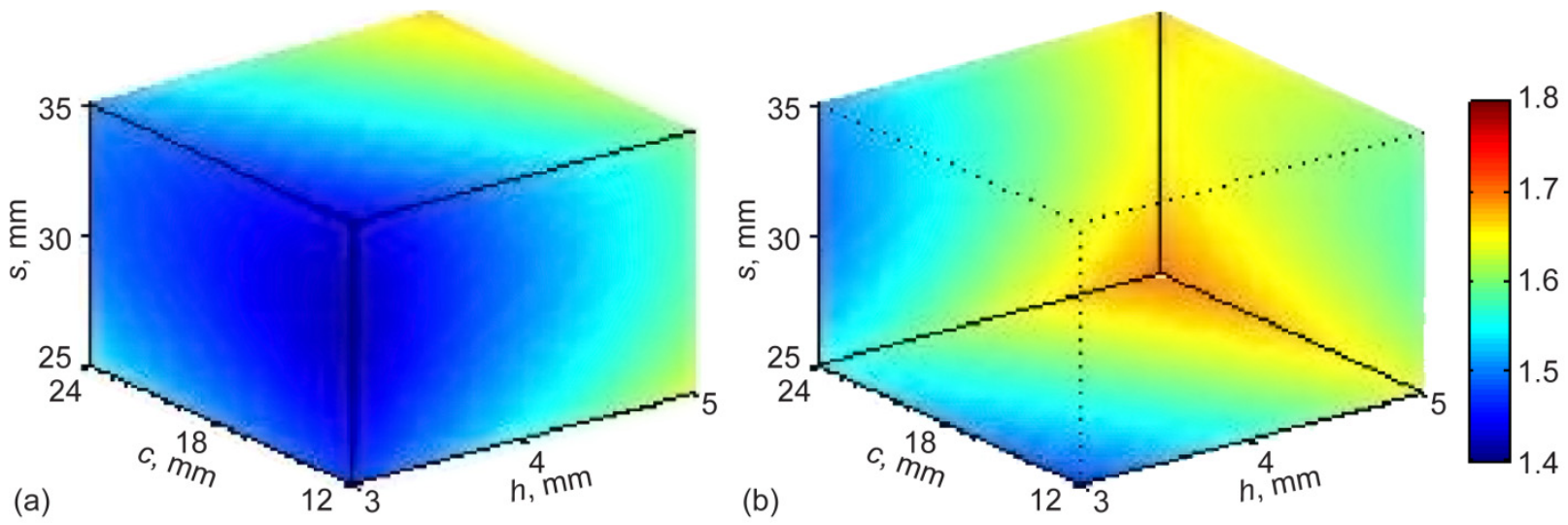

Figure 23.-Central composite DOE model for boundary layer thickness, $\delta$. Levels of $\delta$ are shown as contours. (a) $s=35 \mathrm{~mm}, h=3 \mathrm{~mm}$, and $c=12 \mathrm{~mm}$ surfaces. (b) $s=25 \mathrm{~mm}, h=5 \mathrm{~mm}$, and $c=24 \mathrm{~mm}$ surfaces. 

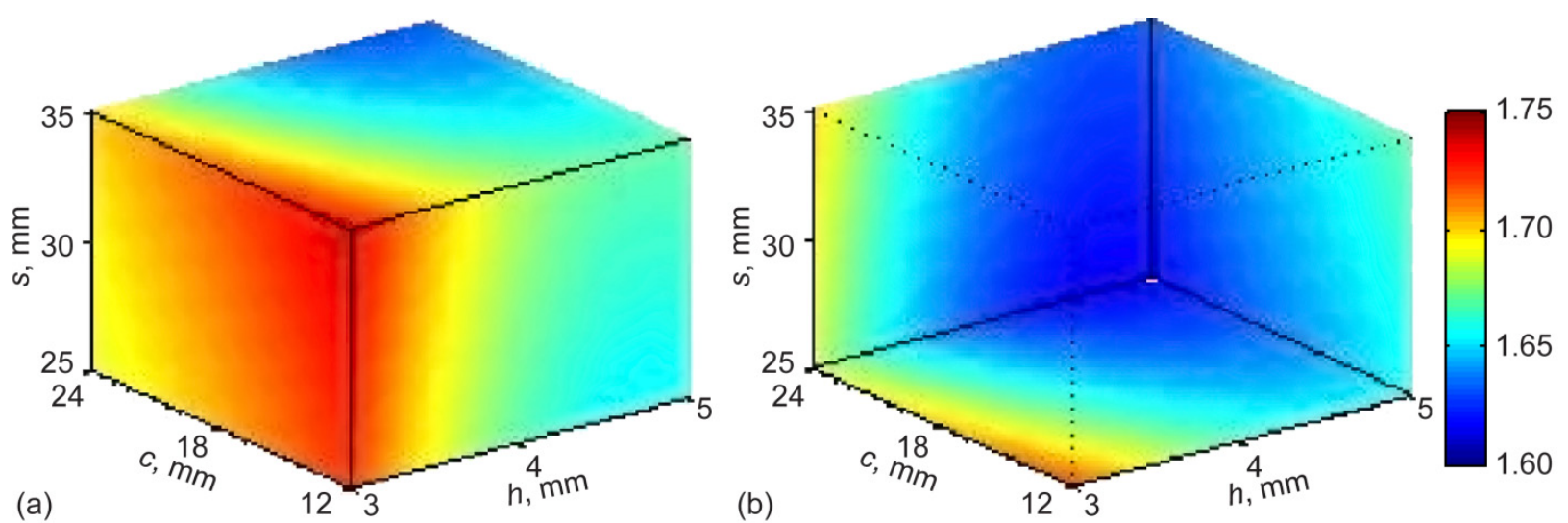

Figure 24.-Central composite DOE model for incompressible shape factor, $H$. Levels of $H$ are shown as contours. (a) $s=35 \mathrm{~mm}, h=3 \mathrm{~mm}$, and $c=12 \mathrm{~mm}$ surfaces. (b) $s=25 \mathrm{~mm}, h=5 \mathrm{~mm}$, and $c=24 \mathrm{~mm}$ surfaces.

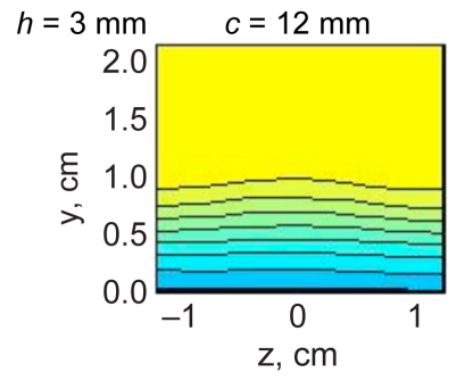

$c=18 \mathrm{~mm}$

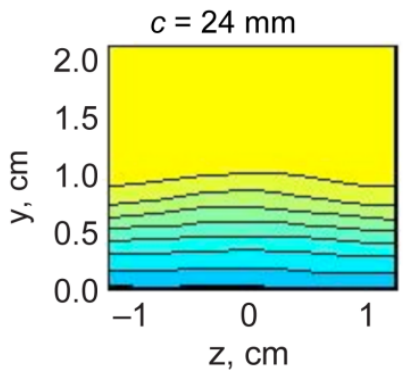

$h=4 \mathrm{~mm}$
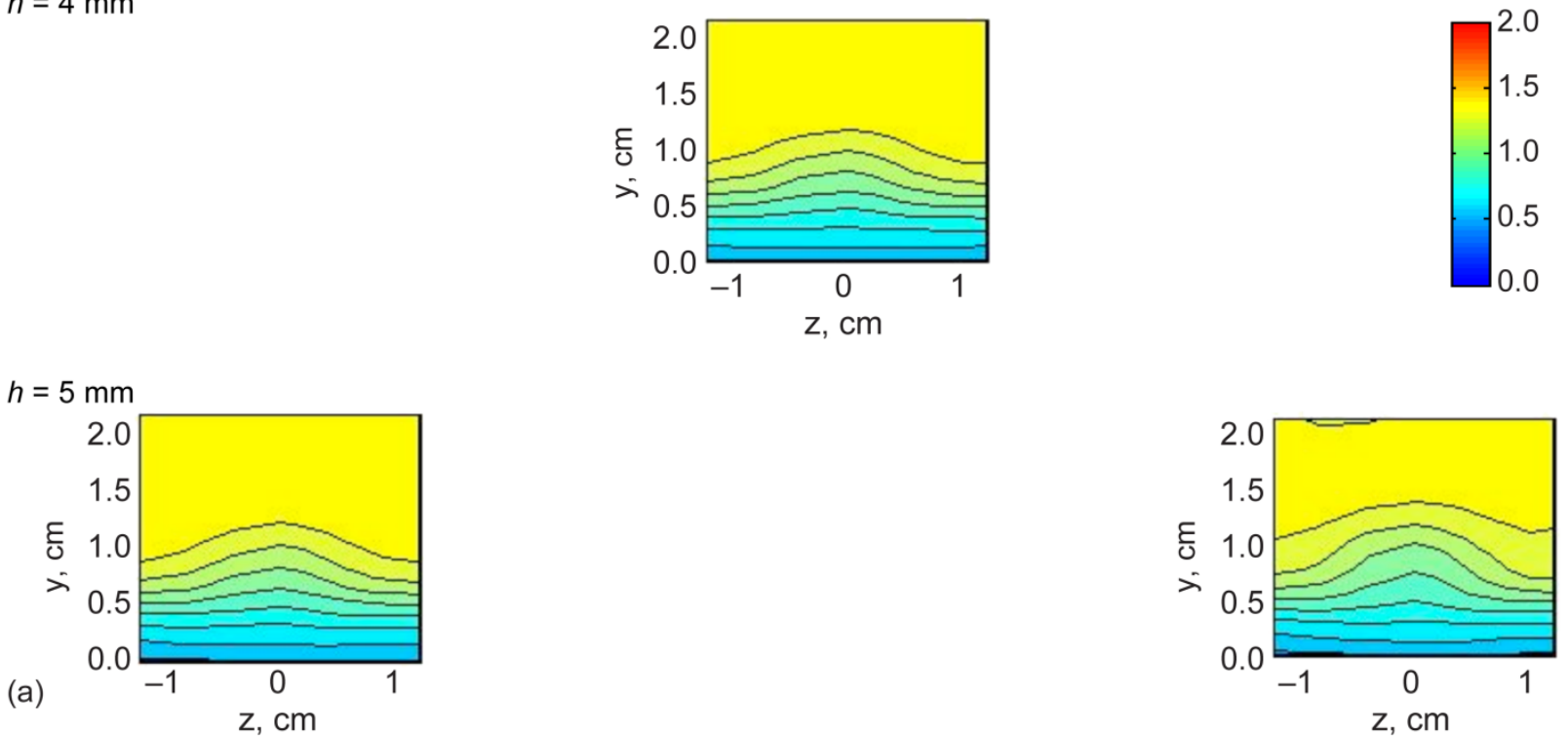

Figure 25.-Contour plots of Mach number, $\mathrm{M}$, at $\mathrm{x}=4 \mathrm{~cm}$ for microramp spacing. (a) $s=25 \mathrm{~mm}$. (b) $s=30 \mathrm{~mm}$. (c) $s=35 \mathrm{~mm}$. 

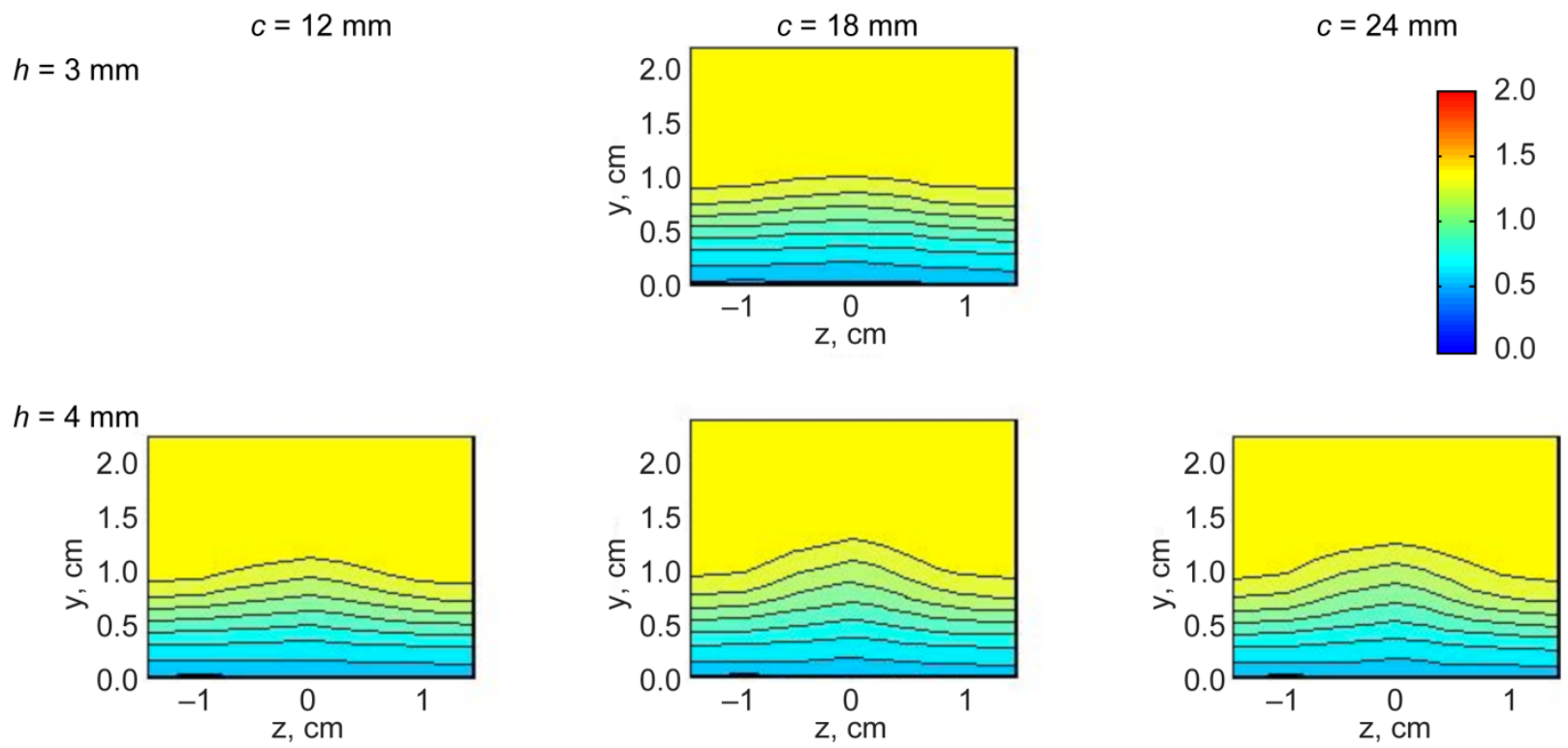

$h=5 \mathrm{~mm}$

(b)

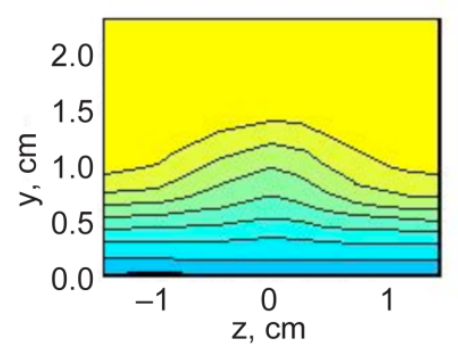

Figure 25.-Continued. 


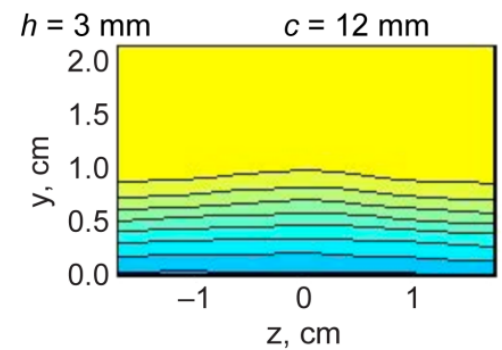

$h=5 \mathrm{~mm}$

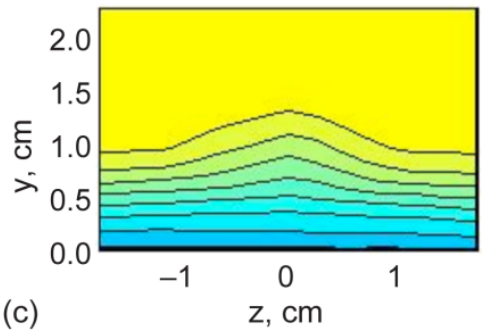

$h=4 \mathrm{~mm}$

(c)

$\mathrm{z}, \mathrm{cm}$ $c=18 \mathrm{~mm}$
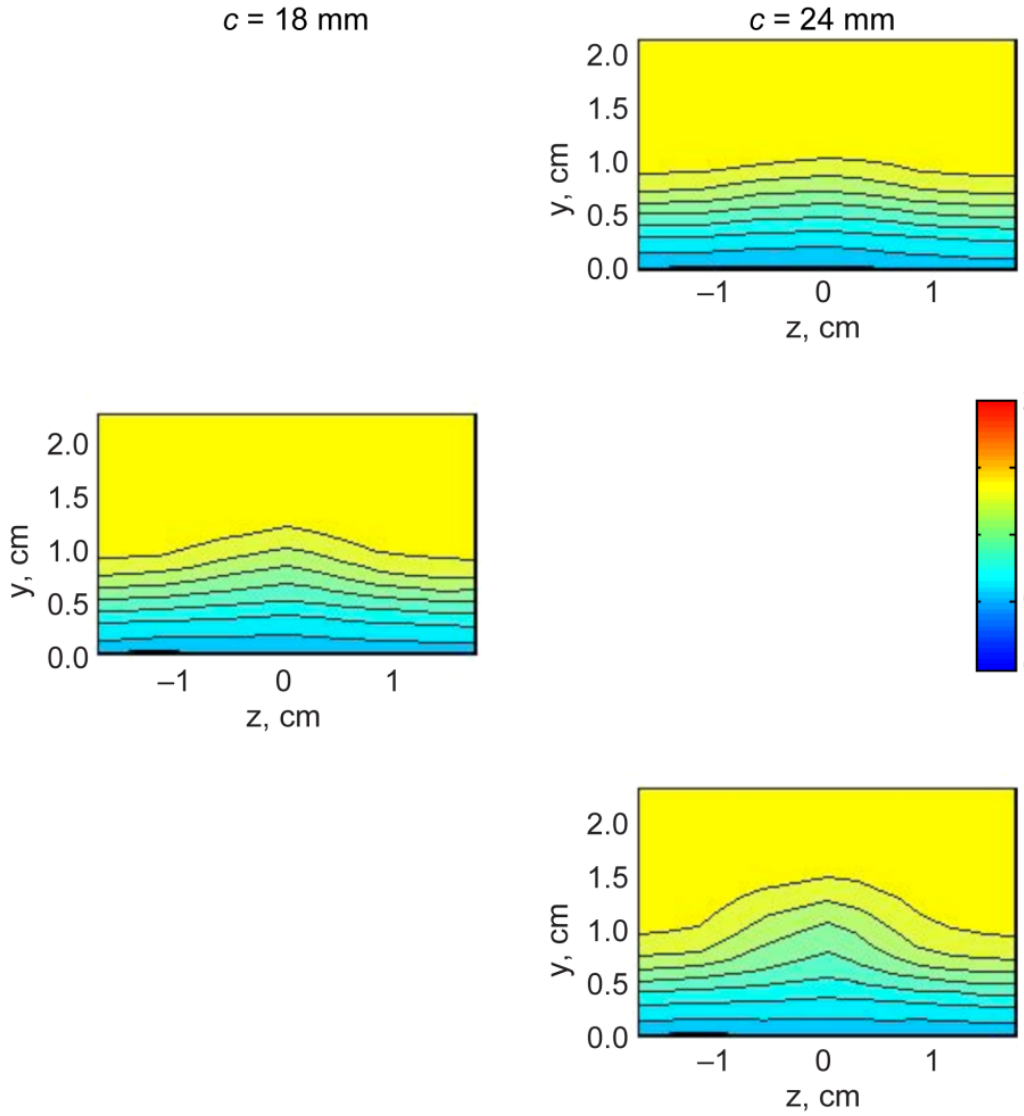

Figure 25.-Concluded. 


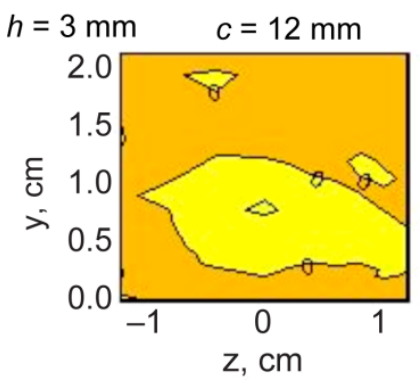

$h=4 \mathrm{~mm}$

$h=5 \mathrm{~mm}$

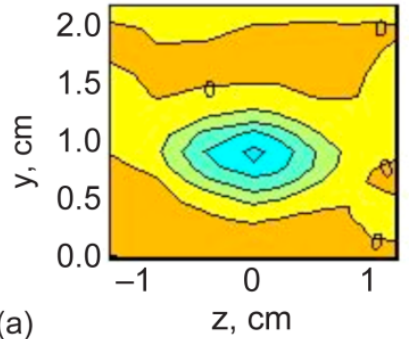

$$
c=18 \mathrm{~mm}
$$
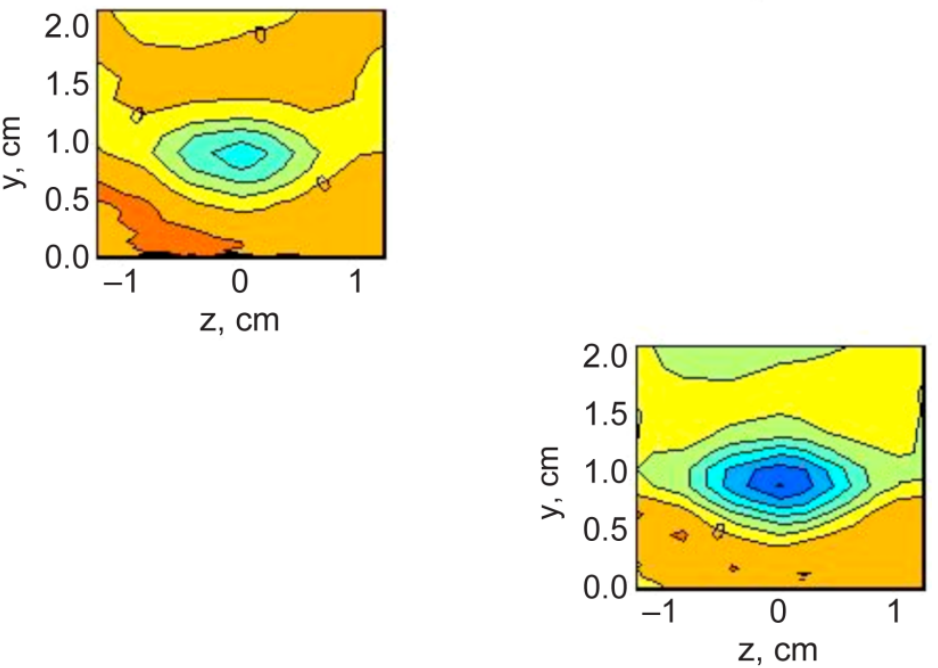

Figure 26.-Contour plots of relative Mach number, M-Mb, at $\mathrm{x}=4 \mathrm{~cm}$ for microramp spacing. (a) $s=25 \mathrm{~mm}$. (b) $s=30 \mathrm{~mm}$. (c) $s=35 \mathrm{~mm}$. Contour lines at the M-Mb = 0 level are marked with " 0 ". 


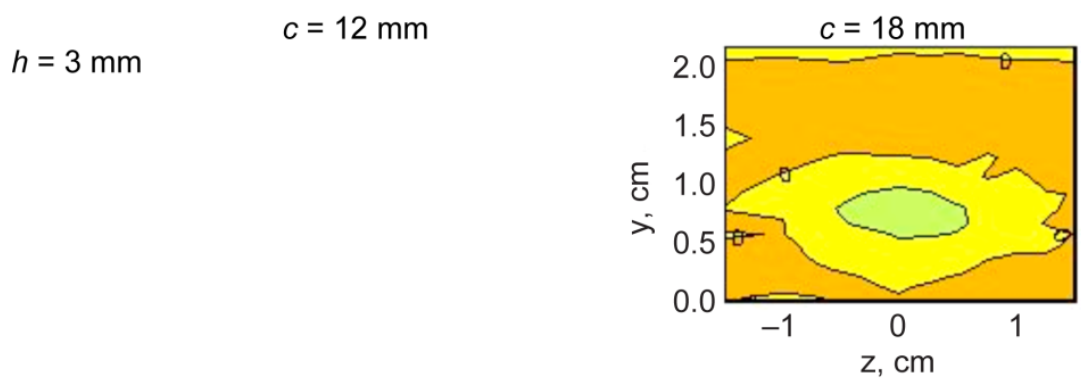

$c=24 \mathrm{~mm}$
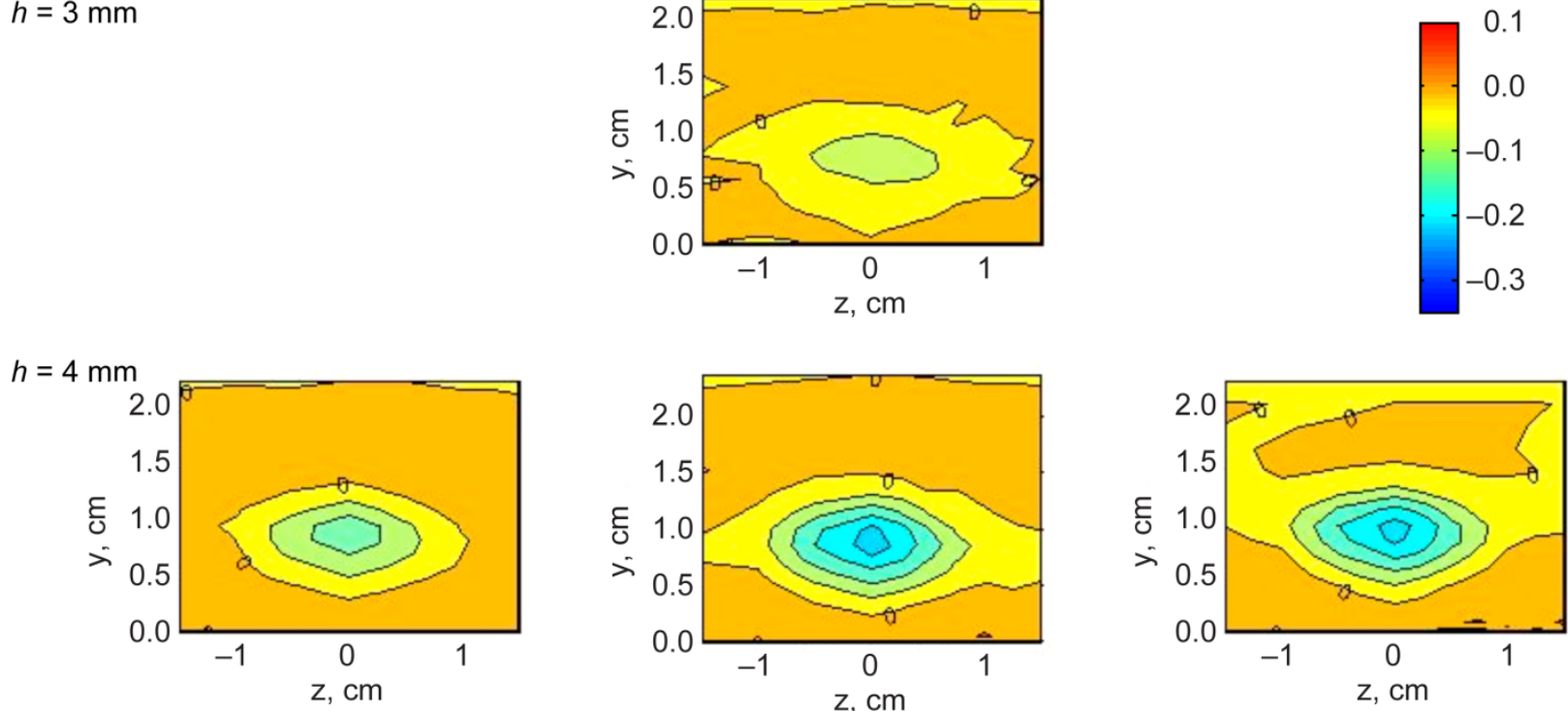

$h=5 \mathrm{~mm}$

(b)

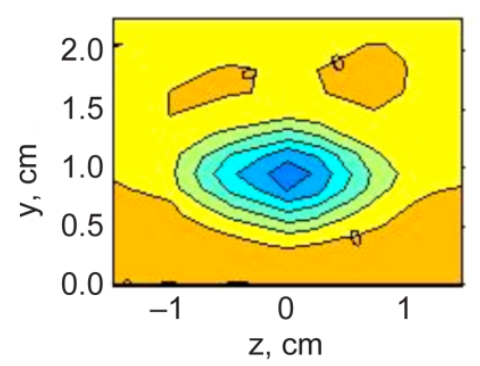

Figure 26.-Continued. 


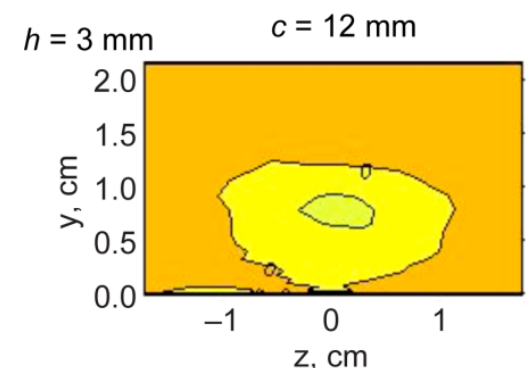

$c=18 \mathrm{~mm}$

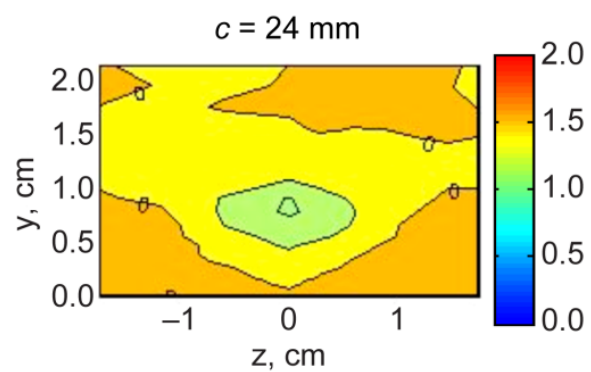

$h=4 \mathrm{~mm}$

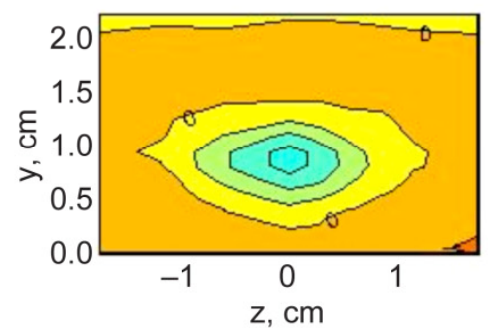

$h=5 \mathrm{~mm}$

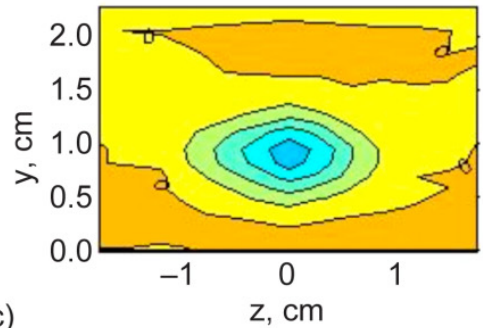

(c)

$\mathrm{z}, \mathrm{cm}$

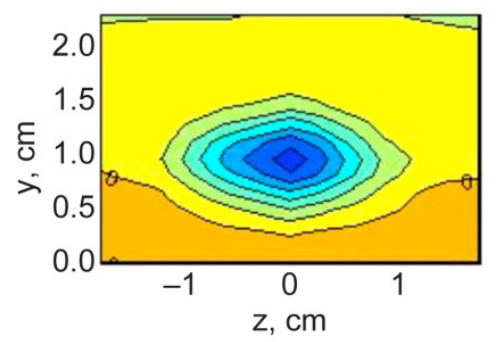

Figure 26.-Concluded. 

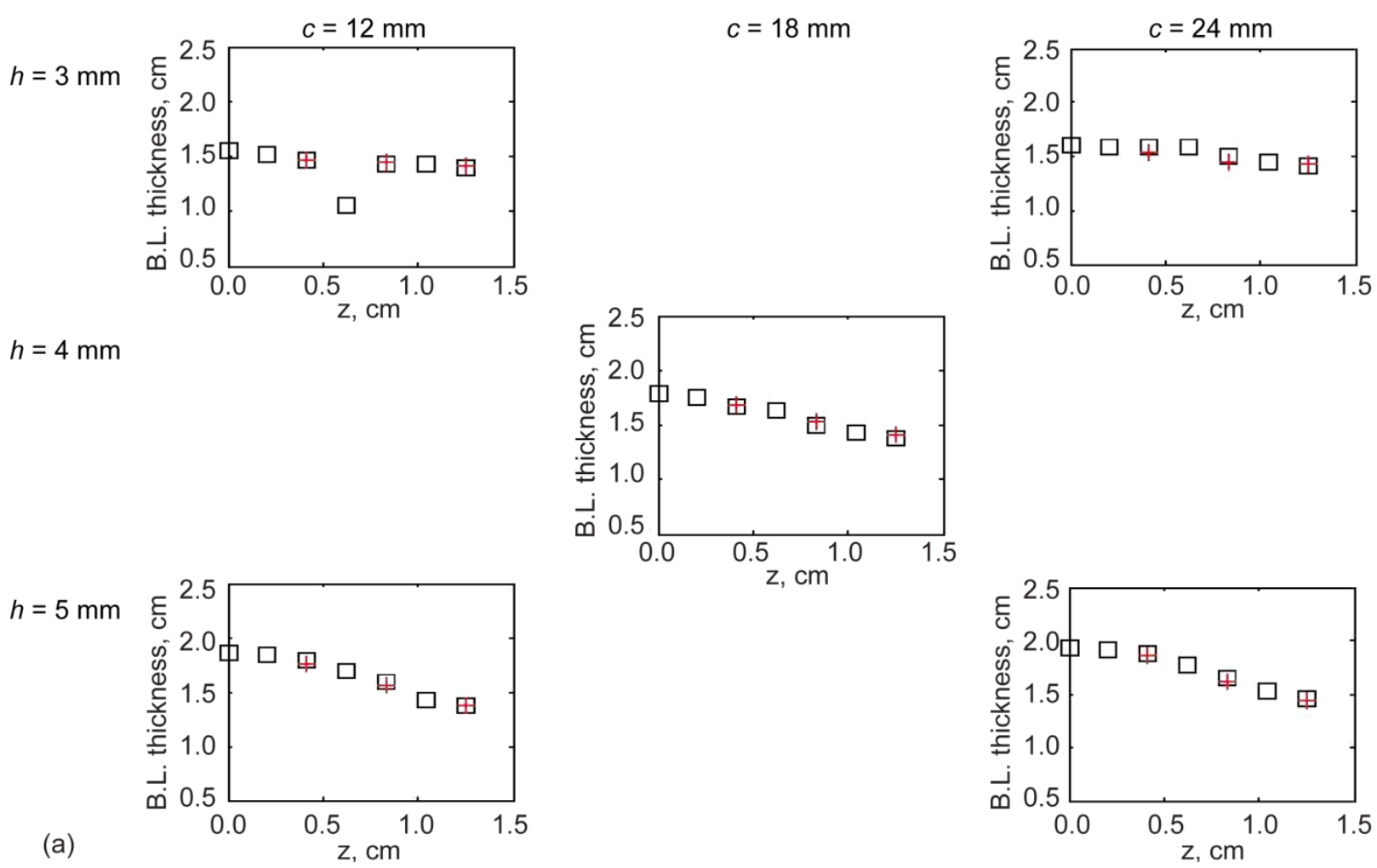

(a)

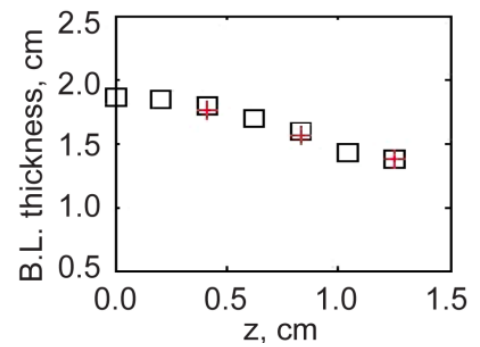

Figure 27.-Spanwise boundary layer thickness, $\delta$, variation with negative $z$ values mirrored across the $y$-axis for microramp spacing. (a) $s=25 \mathrm{~mm}$. (b) $s=30 \mathrm{~mm}$. (c) $s=35 \mathrm{~mm}$. 


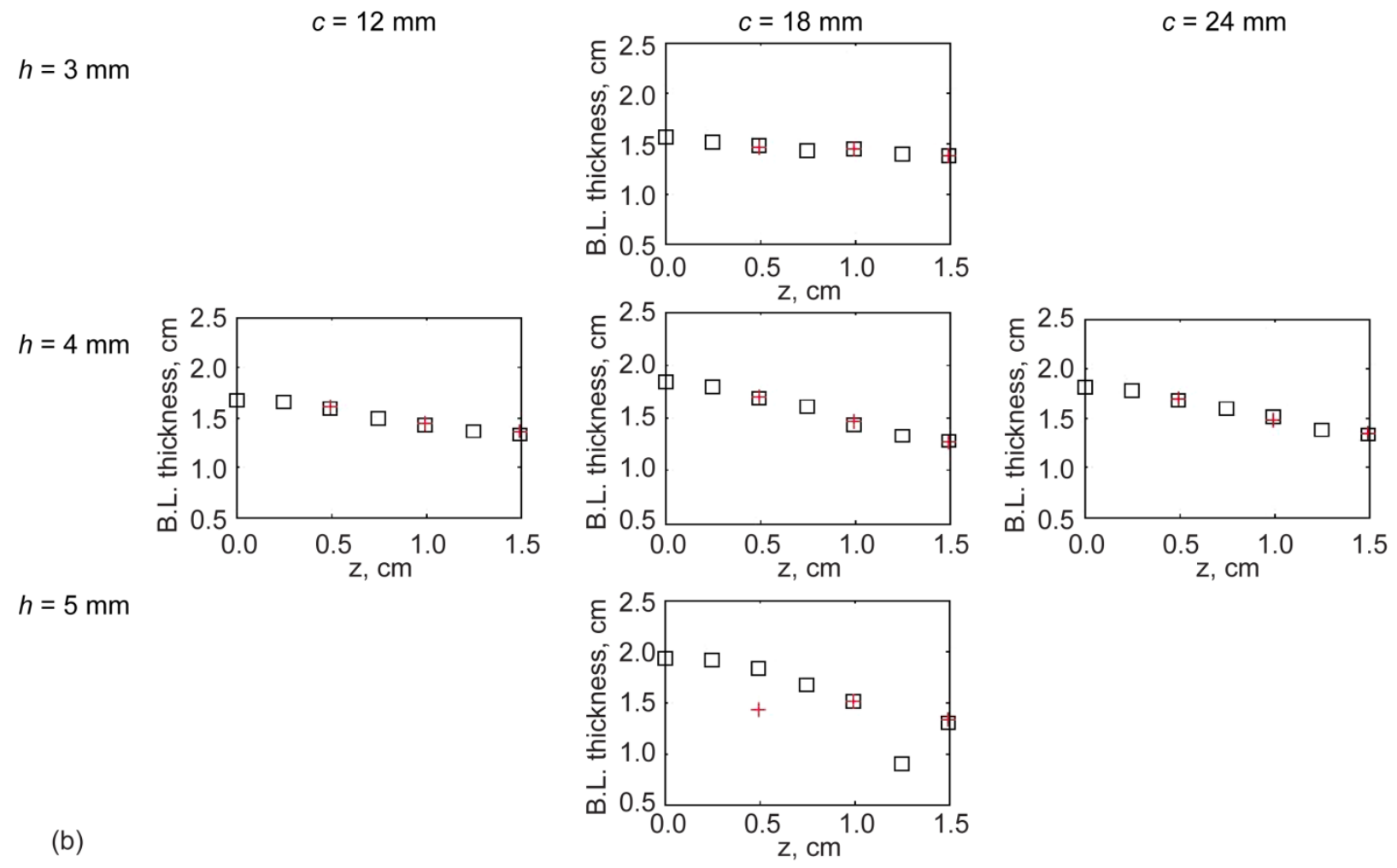

Figure 27.-Continued. 


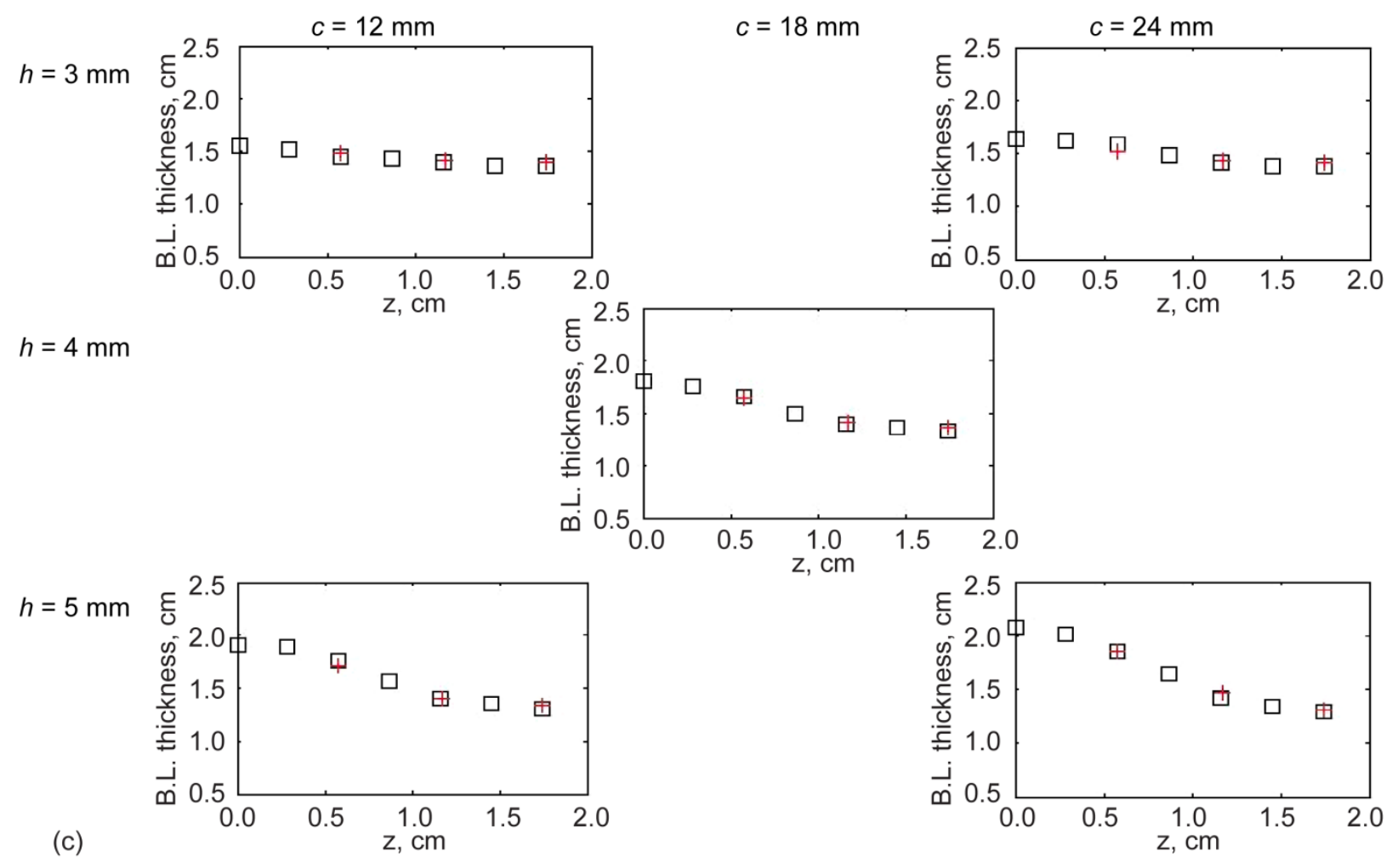

Figure 27.-Concluded. 


\begin{tabular}{|c|c|c|c|c|c|}
\hline \multicolumn{5}{|c|}{ REPORT DOCUMENTATION PAGE } & $\begin{array}{l}\text { Form Approved } \\
\text { OMB No. 0704-0188 }\end{array}$ \\
\hline \multicolumn{6}{|c|}{$\begin{array}{l}\text { The public reporting burden for this collection of information is estimated to average } 1 \text { hour per response, including the time for reviewing instructions, searching existing data sources, gathering and maintaining the } \\
\text { data needed, and completing and revieving the collection of information. Send comments regarding this burden estimate or any other aspect of this collection of information, including suggestions for reducing this } \\
\text { burden, to Department of Defense, Washington Headquarters Services, Directorate for Information Operations and Reports (0704-0188), } 1215 \text { Jefferson Davis Highway, Suite } 1204 \text {, Arlington, VA } 22202-4302 \text {. } \\
\text { Respondents should be aware that notwithstanding any other provision of law, no person shall be subject to any penalty for failing to comply with a collection of information if it does not display a currently valid OMB } \\
\text { control number. } \\
\text { PLEASE DO NOT RETURN YOUR FORM TO THE ABOVE ADDRESS. }\end{array}$} \\
\hline \multicolumn{2}{|c|}{$\begin{array}{l}\text { 1. REPORT DATE (DD-MM-YYYY) } \\
01-11-2009\end{array}$} & \multicolumn{3}{|c|}{$\begin{array}{l}\text { 2. REPORT TYPE } \\
\text { Technical Memorandum }\end{array}$} & 3. DATES COVERED (From - To) \\
\hline \multirow{3}{*}{\multicolumn{5}{|c|}{$\begin{array}{l}\text { 4. TITLE AND SUBTITLE } \\
\text { Experimental Investigation of the Application of Microramp Flow Control to an Oblique } \\
\text { Shock Interaction }\end{array}$}} & 5a. CONTRACT NUMBER \\
\hline & & & & & 5b. GRANT NUMBER \\
\hline & & & & & 5c. PROGRAM ELEMENT NUMBER \\
\hline \multirow{3}{*}{\multicolumn{5}{|c|}{$\begin{array}{l}\text { 6. AUTHOR(S) } \\
\text { Hirt, Stefanie, M.; Anderson, Bernhard, H. }\end{array}$}} & 5d. PROJECT NUMBER \\
\hline & & & & & 5e. TASK NUMBER \\
\hline & & & & & $\begin{array}{l}\text { 5f. WORK UNIT NUMBER } \\
\text { WBS 984754.02.07.03.13.02 }\end{array}$ \\
\hline \multicolumn{5}{|c|}{$\begin{array}{l}\text { 7. PERFORMING ORGANIZATION NAME(S) AND ADDRESS(ES) } \\
\text { National Aeronautics and Space Administration } \\
\text { John H. Glenn Research Center at Lewis Field } \\
\text { Cleveland, Ohio 44135-3191 }\end{array}$} & $\begin{array}{l}\text { 8. PERFORMING ORGANIZATION } \\
\text { REPORT NUMBER } \\
\text { E-16942 }\end{array}$ \\
\hline \multirow{2}{*}{\multicolumn{5}{|c|}{$\begin{array}{l}\text { 9. SPONSORING/MONITORING AGENCY NAME(S) AND ADDRESS(ES) } \\
\text { National Aeronautics and Space Administration } \\
\text { Washington, DC 20546-0001 }\end{array}$}} & $\begin{array}{l}\text { 10. SPONSORING/MONITOR'S } \\
\text { ACRONYM(S) } \\
\text { NASA }\end{array}$ \\
\hline & & & & & $\begin{array}{l}\text { 11. SPONSORING/MONITORING } \\
\text { REPORT NUMBER } \\
\text { NASA/TM-2009-215630; AIAA-2009-919 }\end{array}$ \\
\hline \multicolumn{6}{|c|}{$\begin{array}{l}\text { 12. DISTRIBUTION/AVAILABILITY STATEMENT } \\
\text { Unclassified-Unlimited } \\
\text { Subject Categories: } 02 \text { and } 07 \\
\text { Available electronically at http://gltrs.grc.nasa.gov } \\
\text { This publication is available from the NASA Center for AeroSpace Information, 443-757-5802 }\end{array}$} \\
\hline \multicolumn{6}{|c|}{ 13. SUPPLEMENTARY NOTES } \\
\hline \multicolumn{6}{|c|}{$\begin{array}{l}\text { 14. ABSTRACT } \\
\text { The effectiveness of microramp flow control devices in controlling an oblique shock interaction was tested in the } 15 \text { - by } 15 \text {-Centimeter } \\
\text { Supersonic Wind Tunnel at NASA Glenn Research Center. Fifteen microramp geometries were tested varying the height, chord length, and } \\
\text { spacing between ramps. Measurements of the boundary layer properties downstream of the shock reflection were analyzed using design of } \\
\text { experiments methods. Results from main effects, D-optimal, full factorial, and central composite designs were compared. The designs } \\
\text { provided consistent results for a single variable optimization. }\end{array}$} \\
\hline \multicolumn{6}{|c|}{$\begin{array}{l}\text { 15. SUBJECT TERMS } \\
\text { Compressible boundary layers; Boundary layer control; Vortex generators; Oblique shock waves }\end{array}$} \\
\hline \multicolumn{3}{|c|}{ 16. SECURITY CLASSIFICATION OF: } & $\begin{array}{l}\text { 17. LIMITATION OF } \\
\text { ABSTRACT }\end{array}$ & $\begin{array}{l}\text { 18. NUMBER } \\
\text { OF }\end{array}$ & $\begin{array}{l}\text { 19a. NAME OF RESPONSIBLE PERSON } \\
\text { STI Help Desk (email:help@sti.nasa.gov) }\end{array}$ \\
\hline $\begin{array}{l}\text { a. REPORT } \\
\text { U }\end{array}$ & $\begin{array}{l}\text { b. ABSTRACT } \\
\text { U }\end{array}$ & \begin{tabular}{|l|} 
c. THIS \\
PAGE \\
U \\
\end{tabular} & UU & $\begin{array}{l}\text { PAGES } \\
33\end{array}$ & $\begin{array}{l}\text { 19b. TELEPHONE NUMBER (include area code) } \\
443-757-5802\end{array}$ \\
\hline
\end{tabular}


